\title{
WestVirginiaUniversity
}

THE RESEARCH REPOSITORY @ WVU

Graduate Theses, Dissertations, and Problem Reports

2001

\section{Generic pronouns and their influence on the speakers' language awareness}

\author{
Maike Engelhardt \\ West Virginia University
}

Follow this and additional works at: https://researchrepository.wvu.edu/etd

\section{Recommended Citation}

Engelhardt, Maike, "Generic pronouns and their influence on the speakers' language awareness" (2001). Graduate Theses, Dissertations, and Problem Reports. 823.

https://researchrepository.wvu.edu/etd/823

This Thesis is protected by copyright and/or related rights. It has been brought to you by the The Research Repository @ WVU with permission from the rights-holder(s). You are free to use this Thesis in any way that is permitted by the copyright and related rights legislation that applies to your use. For other uses you must obtain permission from the rights-holder(s) directly, unless additional rights are indicated by a Creative Commons license in the record and/ or on the work itself. This Thesis has been accepted for inclusion in WVU Graduate Theses, Dissertations, and Problem Reports collection by an authorized administrator of The Research Repository @ WVU. For more information, please contact researchrepository@mail.wvu.edu. 
Generic Pronouns and Their Influence on the Speakers' Language Awareness

\author{
Maike Engelhardt \\ Thesis submitted to the \\ Eberly College of Arts and Sciences \\ at West Virginia University \\ in partial fulfillment of the requirements \\ for the degree of
}

Masters of Arts
in
Foreign Languages

Linguistics

Johan Seynnaeve, Ph.D., Chair

Deborah Janson, Ph.D.

Michael Reider, Ph.D.

Department of Foreign Languages

Morgantown, West Virginia

2001

Keywords: Generic Pronouns, Feminist Linguistics, Sapir-Whorf Hypothesis, Language Awareness, Language Change

Copyright 2001 Maike Engelhardt 


\section{Abstract \\ Generic Pronouns and Their Influence on the Speakers' Language Awareness \\ Maike Engelhardt}

The English language is a genderless language in which nouns receive grammatical gender through natural gender assignment. The generic pronoun encoded in English is the pronoun he, which next to its secondary meaning of the generic also has the primary meaning of the third person masculine singular. Following the moderate version of the Sapir-Whorf hypthesis, English speaking societies may therefore be considered androcentric societies, since the unmarked use of the generic he makes everyone in this society male until explicitly proven otherwise. In this thesis I explore the history of the generic pronoun in English and offer suggestions for a change in language awareness which, in the ideal case, could result in a language change in the favor of women in society. 
für bärbel - die jeden tag da war little light still burning 
acknowledgements - danksagungen

i would like to thank dr. johan seynnaeve for the time he invested in helping me with this thesis. i chose one of his probably busiest semesters to write this thesis and pestering him with new drafts every week and expecting feedback on each and every one of them. dr. seynnaeve was not only my thesis committee chair and graduate advisor, he has also become a role model with his vast knowledge of and about languages which i admire to a great extent. thank you for being there with answers all the time! as they say: you're the best!

then i would like to thank dr. deborah janson and dr. michael reider for being members of my committee. thanks to dr janson in particular because she agreed to give further suggestions on some parts of this thesis. she became as valued friend and $\mathrm{i}$ am glad to have met her and that i could convince her to be on my committee. and thanks to dr. reider for being on my committee and for being one of the most challenging teachers in this program. without him i probably would not have come up with this thesis in the first place.

i need to thank dr. susanne niemeier for sparking the fire of linguistics in me. without her contagious enthusiasm on the subject of cognitive linguistics i would have most likely dropped linguistics after my first semester and would never know about this strange passion inside of me. thank you so much!

dr. laura brady and dr. patrick conner from the WVU english department also deserve my thanks because they invested their time in me and my work even though i am not even a student of theirs. their input was extremely valueable for me. thank you for taking the time to tell me things i didn't know and for teaching me how to write.

a very special thanks goes to dr. gerhard bach, who gave me the opportunity to go to west virginia in the first place.

apart from drs. and profs., i need to thank the people who went through my two years with me and provided comic relief which almost made morgantown feel like home. my various roommates and friends in the german embassy: maren, jonas, sven, karsten, brian, tanja, astrid, jason, christiane, jessica, stacy and lisa. ein besonderer dank geht auch an agnes und an irina, die durch ihre staendige verunstaltung der deutschen sprache meine gedanken auf diverse missstaende im deutschen gelenkt haben. ohne sie wuerde ich wie die oechsin vorm berge stehen. im besonderen muss ich auch astrid danken, die mir nicht nur zu einer ausgewachsenen kaffeesucht verholfen hat, sondern auch mit aufmunternden worten die tage verkuerzt hat.

ausserdem danke ich meiner mitstreiterin susanne; fuer spaete abende im buero, hinweise auf sonnenuntergaenge, dancing queen in dritten stock, bier auf dem weg nach hause, und fuer ihre konstante, aber immer konstruktive kritik an meiner arbeit. ohne sie haette ich diese zeit nicht zu einem solchen ende gebracht.

abschliessend danke ich meiner mutter dafuer, dass sie mich in allen meinen unternehmungen unterstuetzt, auch wenn nicht immer ganz klar ist fuer was es einmal gut sein wird; und baerbel, dass sie mich zwei jahre hat gehen lassen, und mich jederzeit in ihr leben hat plumpsen lassen, nur um mich zwei wochen oder zwei tage spaeter wieder zum flughafen zu bringen.

thanks, y'all, for everything you did and are! 
Table of Contents

Title Page

Abstract

acknowledgements

Table of Contents

iv

0 . Introduction

1.0. Terms and definitions

1.1. Generics

1.2. Pronouns

1.2.1. Function of pronouns

1.3. He vs. She

1.4. He vs. he/she

1.4.1. He vs he or she

1.5. He vs. they

1.6. She vs. they

1.7. Sex vs. Gender

1.7.1. Sex vs. Gender within language and linguistics

1.7.2. Sex vs. Gender outside of language and linguistics

2.0. History of generic pronouns

2.1. The 18th century grammarians

2.2. Generic pronoun variations

3.0. Language and Culture

3.1. Sapir and Whorf - Anthropology and Linguistics

3.2. The Sapir - Whorf Hypothesis

4.0. Feminism and Linguistics

4.1. Sex biased language - sexist language $\quad 58$

4.1.1. Language and gender 61

4.1.2. Language and sex 65

4.2. The feminist understanding of the Sapir-Whorf hypothesis 68 
4.2.1. The need for a new pronoun $\quad 71$

5.0. Now what? The 'chicken and the egg' question. 73

5.1. A change in pronoun, a change in awareness?

5.2. A change in awareness, a change in pronoun? 78

6.0. Conclusion 82

$\begin{array}{ll}\text { References } & 88\end{array}$

$\begin{array}{ll}\text { Appendix } 1 & 92\end{array}$

$\begin{array}{ll}\text { Appendix } 2 & 93\end{array}$ 
0. Introduction

The function of pronouns has been encoded in language as long as there have been rules for the use of language. Pronouns are important for reference in sentences. They make sentences shorter and more specific and they define some very important aspects of the nouns they refer to. One of these aspects is that of gender. English uses the masculine pronoun he as its generic and unmarked pronoun. He in this function was encoded in the language several hundred years ago, and has kept and claimed this space successfully over the years, being reinstated in its place by language purists whenever new pronouns were introduced and sometimes used by some speakers as an attempt to change the generic pronoun in English. These attempts were rather feeble and he successfully kept its position in English. Others have complained about he being the generic and unmarked pronoun of English. In particular, feminists have repeatedly pointed out that the position of the generic pronoun can and should not be taken by a pronoun with such a strong primary meaning as he. He as the generic pronoun holds therefore two meanings; the primary as the third person singular masculine pronoun and the secondary as the generic and unmarked pronoun of English.

A large amount of literature concerned with the generic he has been produced in recent years, and I have chosen only a few, but, in my opinion the most influential works as an underlying basis to this thesis. The leading question of this thesis is that of the speaker's awareness of English and the influence of the unmarked use of the masculine pronoun on this awareness. How can the use of a pronoun influence a speaker in their perception of the world around them and in which ways does a pronoun influence the 
positions of men and women in society. In order to answer these questions and also in order to call the function of pronouns into the conscious awareness of my readers, I will use singular they as the generic pronoun in this thesis. I believe that there are grammatical reasons for the generic pronoun he, but I also feel that women are left out of this language use. I agree with some grammarians in the notion of he or she as a generic to be awkward and cumbersome and I have also noticed a strengthened use of singular they in my language environment. I find myself using they as a generic singular pronoun very often and I believe that my personal use of a plural pronoun turned singular in speech should be presented in my written work as well. Singular they has a certain history as a generic pronoun in English, which I show in the beginning parts of this thesis.

Dennis Baron's book Grammar and Gender (1986) gives a comprehensive history of the generic pronoun he. From the prescriptive grammarians in the $18^{\text {th }}$ century, Baron shows the many instances of neologisms for the epicene pronoun. He points out that there have been several attempts to change the generic pronoun to either a different pronoun in the given set of pronouns, e.g. singular they, he or she, etc., or to a newly invented pronoun, which was naturally without prior associated meaning. However, Baron's conclusion is that epicene pronouns have failed in English and that the generic and unmarked use of he is still alive and well.

Robin Lakoff wrote with Language and Women's Place (1975) a highly influential book on the position of women in society and the relation of this position to the language of this society. Her book and excerpts from it are still quoted in many books and articles today, and her arguments are still vividly discussed in linguistics. And while Language and Women's Place seems to be one of the first stepping stones of feminism 
in linguistics, it also appears to be the most controversial theory of women in language. Casey Miller and Kate Swift also wrote two important books on language and women and adherred some of Lakoff's important points. In Words and Women (1976), Miller and Swift draw the picture of women in society as oppressed due to the masculine bias in language. Their feminist standpoint on the generic pronoun he could not be clearer. They point out that we not only have he as a generic, but we are also all members of mankind, specimen of a race which believes in the superiority of man and puts women in almost every figure of speech into second position. Miller and Swift published the Handbook of Nonsexist Writing in 1980. This was a continuation of their theory of women's oppression through and within language, and this handbook shows the many possible ways of avoiding sexist language use in English. The writers claim that the language awareness of speakers is influenced by their choice of vocabulary, or rather, by the vocabulary they are conventionally allowed choose.

According to this theory, women are marginalized in language. They are marginal members of humankind since they are not the norm, and the norm being male. Every person is male until proven otherwise. This is evident from language. A very interesting article written by Fatemeh Khosroshahi, "Penguins don't care, but women do" (1989), deals already in its title with this marginalization. Penguins live on the outskirts of the semantic field for bird, just like women allegedly live on the outskirts of the semantic field for man. Penguins are birds, but they cannot fly, and probably do not appear in any imagery provoked by the word bird. Women are marginal because of the above given reasons. We talk about man, mankind and his inventions, his strength, but also about his ability to raise his young. If we stay within this terminology, we end up talking about 
man breastfeeding his young to nourish them, and at this point it gets a little ridiculous, and one really has to question why English is in fact so male-centered.

In my thesis I will turn to Deborah Cameron and her book on Feminism and Linguistic Theory (1985). In her conclusion she correctly points out that the oppression of women in language through men has to be a myth. If the claim of oppressed women is followed through, we need to also imagine a completely equal communication system, since this complete equality must have been a starting point for society at some point in time. Without equality we cannot understand oppression. This equalitarian system would be without strong and weak, without powerful and poor, it would be a system that is hypothetical. This equal system, in which there are no differences between the speakers, or language users, must be a system in which there are also no differences between the sexes. One of the resulting questions then has to be whether such a system is desirable at all. What would we be without differences? Nevertheless, if there were the possibility of creating such a system or a system even close to or closer to equality than it is the case today in the English speech community, then it should certainly be advised to strive for it. I personally do not believe that such a system ever did or ever will exist. Women and men use language everyday, and both exert their power of choosing certain speech items and neglecting others. Therefore men are certainly in no position to be the only influence on such a large and highly independent concept like language. The prescriptive grammarians who encoded he as the generic pronoun in English were men, and they certainly had their own reasons to choose the masculine pronoun as the generic, but I do not believe that they were even aware of the results, and that it was their action of encoding that created so much bias in language as we find it up until today. 
The threaded theme of this thesis is my own language awareness. As a non-native speaker of English, I had the opportunity to study this language in a very structured way, just by learning words and their connected meanings. For the pronoun he the primary meaning, that of the masculine third person singular pronoun, seemed to be the most salient. As a language learner I was surprised to see it being used as a generic term, and was even more surprised to see singular they take its place over time. I will not only investigate the use of he, but also its alternatives, she, he or she, s/he, they and some neologisms. I will look at different viewpoints on language and culture and I will question the relation of the pronoun use and the speaker's language. In my final chapter I will make my own suggestions for how to overcome sex-bias in the English language. I want to, however, make clear, that I do not see my suggestions in the light of language and grammar prescriptivism, since prescriptivism goes against every understanding of language that I call my own. I do not believe in active language change through rules and regulations. I believe that language changes with time, and that the speakers' language awareness may influence the speed of change. Raising awareness has much more influence on the choice of vocabulary than prescribed grammar rules could ever have. 


\subsection{Terms and definitions}

Before starting this thesis and discussing the problem of the generic pronoun he in English, it will be useful to explain certain terms and their definitions. These terms will carry through the main part of this work, and since their understanding is vital for the understanding of my thesis, I will try to delineate their meaning and point out their importance for my thesis ${ }^{1}$.

When talking about a subject like the generic he and its difficulties in English, it is most significant to zero in on the characteristics of language that make its application possible. For one, we have to distinguish between gendered and genderless languages. Gendered languages like French or German have nouns that are masculine, feminine and/or neuter.

\begin{tabular}{llll} 
& French & German & English \\
\hline \hline masculine & le fils & der Junge & the boy \\
feminine & la femme & die Frau & the woman \\
neuter &.$/$ & das Kind & the child \\
\hline masculine & un fils & ein Junge & a boy \\
feminine & une femme & eine Frau & a woman \\
neuter &.$/$ & ein Kind & a child \\
\hline
\end{tabular}

The gender-assignment in these languages is not necessarily natural (compare natural gender below) or entirely logical (Baron, 1986, p. 109). For example the German 
word for woman is die Frau, and thus feminine, but her skirt is der Rock, masculine ${ }^{2}$. It would make sense, logically, to give everything that has to do with females the feminine gender in grammar, and the masculine for all males. The skirt in German is an example that logic has not been followed in the assignment of gender for nouns. Objects can hold either masculine, feminine or neuter gender. Tables are masculine, beds neuter and the sun feminine in German ${ }^{3}$, but in French tables are feminine, beds are masculine and the sun is masculine. The gender assignment of these languages seems to be grounded on more ideological reasons than grammatical reasons, and I would suggest discussing the ideological reasons and their influences on grammatical gender of nouns at another point and not here. It may in fact be this ideology which leads to the positions of men and women in society, but at this point I would like to focus on the grammatical gender of nouns.

The gender of nouns in a gendered language is expressed through the articles and sometimes the adjectives inside the noun phrase (NP). In the table above the definite and indefinite articles in French and German show the differences between the gendered nouns. In English the nouns or articles are not classified through grammatical inflection but they are classified semantically, depending on their coreferential relations with pronouns (Quirk et al., 1985). In addition to the articles in gendered languages, the attributive adjectives for these nouns must also agree in gender. Attributive adjectives have to go through declination together with the noun. Declination for nouns means that they may be inflected for case, number and gender. German, for example, has four different cases (nominative, dative, genitive and accusative). Case is normally visible through case endings on both the noun and the article. If adjectives are involved, they will also, most of the time, show the case ending. For example, the German equivalent 
for the old man (masculine), the old woman (feminine) and the old car (neuter) in nominative, genitive, dative and accusative case are as follows ${ }^{4}$ :

masculine feminine neuter

$\begin{array}{llll}\text { nominative } & \text { der alte Mann } & \text { die alte Frau } & \text { das alte Auto } \\ \text { genitive } & \text { des alten Mannes } & \text { der alten Frau } & \text { des alten Autos } \\ \text { dative } & \text { dem alten Mann } & \text { der alten Frau } & \text { dem alten Auto } \\ \text { accusative } & \text { den alten Mann } & \text { die alte Frau } & \text { das alte Auto }\end{array}$

In the process of declination the nouns receive different suffixes (in the genitive masculine and in the genitive neuter), which are also in this course applied to adjectives and mainly to determiners. The example above displays the application of definite articles (der, die, das, etc.). This type of suffixation applies to indefinite articles as well in German (ein, eine, ein, etc.).

Apart from grammatical gender it is important to find out how grammatical gender is perceived. For example, do German speakers perceive a table (der Tisch) to be masculine but the sea (die See) feminine? In other words, are male attributes applied to a masculine status of a noun, in this case Tisch? The language awareness for the native speaker is determined by their knowledge of their language, and probably also by their knowledge about their language. This means that speakers who consciously know about gender assignment in their language will view the fact that certain nouns are of a certain gender as a grammatical attribute of the language. I belive that the awareness of these educated speakers is a different awareness from that of speakers who do not know about the assignment. The first speakers might question the assignment while the latter speakers take it for granted and do not question this grammatical assignment. 
Returning to English and the problem of the generic pronoun, knowing that he is the masculine pronoun might change the understanding of he in a generic sense. I will come back to this changed language awareness in chapter 5 of this thesis.

The other side of the pendulum are genderless languages. These languages have no obvious grammatical gender applied to nouns, articles and adjectives, and these nouns, articles and adjectives do not receive special gender endings. In these languages, other forms of gender are used, namely natural gender or common gender. Natural gender is determined by the actual, mostly biological gender of the object. An exception to the fairly well regulated assignment is the nonreferential gender of some NPs. I will talk more about nonreferential gender in section 1.7.1. in this chapter of my thesis. In languages with natural gender assignment, a girl will always be referred to by the pronoun she, and a boy will always be referred to as he as the grammatically correct pronoun ${ }^{5}$. An animal is referred to by it until its biological sex is specified. This is a rather logical and indeed natural way of assigning gender in language. However, the problem of gender assignment starts with common gender words like teacher and friend.

Deborah Cameron $(1985,1985 a)$ gives the example of newspaper headlines in which common gender words are used, but different words, modifiers, are still applied to show the difference between "people and women". 6 She points out that even though common gender words are used in these headlines (people, survivors, etc.) these words only refer to men. If women are involved, then they will be specially noted. E.g. "A coloured man subjected to racial abuse went berserk and murdered his next door neighbour's wife with a machete, Birmingham Crown Court heard today" (Cameron, 1985a, p. 26). The common gender word neighbor is assumed to be masculine in this 
headline. If neighbor were considered feminine, most English speakers would consider this odd and the sentence would probably not appear in a newspaper headline. The fact that neighbor is masculine is a good example of the precedence of men to women. It was not the man who was murdered but it was the woman, the female neighbor, who became the victim. She is not only mentioned after the male neighbor, but it also appears as if she is some sort of attribute to him, or maybe a piece of his property. The non-sexist headline would probably have been something like this: 'A coloured man subjected to racial abuse went berserk and murdered his next door neighbour with a machete, Birmingham Crown Court heard today. The victim leaves her husband and children behind'. But this non-sexist version already requires another sentence to further specify the sex of the victim. This may serve as evidence for the androcentricity of English. I will return to androcentrism in language at a later point in this thesis.

Common gender words are supposedly words that are not marked for gender and are applicable for all natural genders and biological sexes. Evidently, even these words carry a certain natural gender connotation and are, most of the time, somehow altered for the female member of the group. Women are mentioned additionally. This mentioning can take various forms in English. It is possible to add modifiers like Lady-, Woman- or Female- for compound words (e.g. Lady lawyer, female friend). These modifiers, however, are sometimes considered diminutives of the primary meaning. Lady and girl are euphemisms for the term woman and deny women their sexuality, maturity and capability (Henley, 1987). To compound nouns of professions with these modifiers most of the time takes some of the value and prestige away from the meaning of the word. Suffixes such as -esse, -ette, or -ine ( actresse, suffragette, mistress, heroine, etc. ) are another way to modify nouns. As becomes obvious from this 
discussion, the assignment of natural gender happens more for semantic reasons than because of formal characteristics of the words. Even in genderless languages, which claim to use the fairest of all gender assignments, where nouns are assigned their gender naturally, some nouns are more equal than others, and thus receive the masculine, the claimed unmarked and most 'salient' gender assignment of those assignments possible. This behavior of the marking of nouns is referred to as sex marking.

Sex marking in English happens at the noun and pronoun level. The examples given above of altered common nouns with feminine prefixes or suffixes show the effects of sex marking.

Since this marking involves women more often than men, it has led to the charge that English is a sexually biased tongue, which singles women out, making them as a rule invisible through the use of the generic masculine, yet sometimes forcing visibility on them through such as (sic!) words as authoress, suffragette, and chorine in order to belittle or repress them (Baron, 1986, p. 111).

Baron clearly states the major complaint of women in linguistics, which basically is that it is to no surprise that women are oppressed in languages which are male-centered, because of this bias in language. Women will be belittled and repressed because of the more frequent masculine gender asssignment for nouns.

There is a claim that languages with grammatical gender limit such open sex marking and thus discrimination is less likely to occur. Casey Miller and Kate Swift write in 1977 that speakers of languages with gender assignment that is basically unrelated to sex are much more sensitive to generic terms and may find the use of man and he 
sexist and biased as the generics of English. This is a strong claim towards the relation between language and thought as expressed in the Sapir-Whorf hypothesis. But more on this at a later point.

Nevertheless, one point should not be forgotten when talking about sex marking. The markedness theory of language is a much disputed one. The markedness theory says that some forms "will always be found earlier or more frequently than others." (Cameron, 1985, p. 67). For linguistic items to be able to receive the title of the unmarked, several criteria have to be met. Unmarked items must possess the ability to be used generically, have neutrality in meaning, and they must display a higher frequency of occurrence than the unmarked variant (Cameron, 1985). This leads to a rather circular argument for the generic he: It is unmarked because it is generic and it is generic because it is unmarked. This regulation for the generic pronoun applies to English, but in some other languages, for example the Native American language Tunica, which was spoken in Louisiana, the feminine is the unmarked form (Cameron, 1985). Neutrality in meaning cannot apply to he, because there are no instances of neutral meaning when it comes to the masculine personal pronoun. Frequency in occurrence for he cannot be given too much value either since we have discussed above that the assignment of gender in English is for natural reasons and therefore rather free in and of itself. English assigns gender on biological grounds (if the biological sex of the referent is known) and sometimes ideological grounds (e.g., cities and countries in English are feminine). Since we assign the masculine sex because of reasons that are outside of language, we have to take these outside reasons into account when we want to talk about the frequency of occurrence for a certain sexmarked form. 
After talking about gender for a long time now, it becomes finally necessary to define the term. Gender has many different definitions. But both in and outside of language, gender may be viewed as a construction of some sort. Outside of language, in the life of people, gender is a social construction. It is a frameset in which every person should and does fit. Gendered subjectivity starts in childhood, when boys and girls start to develop a certain belonging to a gender group. This results in a certain way of speaking, moving and dressing, and may further be refined in choice of words, tone and volume of voice and, to a certain extent, the pitch of a voice. The difference between sex and gender is such that sex is biologically assigned whereas gender may be chosen and sometimes completely changed during life.

Gender in language is a grammatical aspect of a language, which affects content words and may change them accordingly. "Grammatical gender is formal whereas natural gender is semantic" (Cameron, 1985a, p.20, italics in text). Sex in language is, however, not a grammatical aspect, but rather a topic. Language and sex talks more about the sex of the speaker and listener than of the grammaticality of language. This leads into discourse analysis, which to some extent also involves the choice of words for male and female speakers, but which leaves out the problems discussed here, where I focus more on language awareness and the semantic load of pronouns.

Sociolinguists are striving for a definition of the difference between sex and gender. This difference is sometimes less than obvious and the attempt to define either term can become very tedious since a lot of discussion about gender in language is actually a discussion about sex-specific language characteristics. The line between sex and gender can be very fine at times and sometimes it seems to disappear altogether, but it is important to recognize the difference between social gender and grammatical gender. 
The social gender may influence the language use and the choice of vocabulary, but the grammatical gender is applied to words through rules and is used by speakers of both sexes.

There have been very early writings by women who saw flaws in language when it came to gender and generic pronoun assignment, but especially since the 1970s the feminist movement had an enormous impact on the study of language. Most of the inspiration for this thesis stems from the work of feminist linguists from the 1970's. Feminists in linguistics can be, like many things connected to language, traced back over many years. The 1970's brought forth a massive amount of work done on the relation of language to the position of women and society, and I can only refer to a rather small selection of this work in this thesis. But what makes for the difference between feminist linguistics and 'generic' linguistics?

To define feminism in general and a feminist in particular is not an easy task. A feminist, in a short and handy definition, is one who cares about removing restrictions on women that lead to discrimination against women". "Feminist scholars are sometimes accused of having a political agenda, often by those who believe strongly in objective knowledge" (Bing, 1991, p. 13). The political agenda claim is most certainly valid. However, the feminist aspects of scholarship and academia need to be closely inspected. If there is indeed a political aspect to them, then they are not much different from any other viewpoint, since politics is omnipresent anyway. The question to be asked is that of the distinction of the feminist politics to any other political agenda. In which ways is feminism different from other groups and how do feminists change the approach to problem solving to make them different from other groups? 
For many feminist writers, language played a major role and was analyzed frequently (e.g. Deborah Cameron, Casey Miller \& Kate Swift, Deborah Tannen, to name just a few). These writers correctly detected the enormous influence of language on society. Language carries political messages and the way these messages are encoded in language influences their success in society. One of the main reasons for feminists to write about linguistics is certainly the gender bias in language and its impact on society.

A persistent problem with the English language is in fact the generic and unmarked use of the personal pronoun he. And because of the many writings on this pronoun, I shall now show its functions, alternatives, history and impact on the speakers' perception of the world surrounding them.

\subsection{Generics $^{8}$}

The use of generics in language is basically the attempt to generalize speech items that display a high frequency in the use of the language. The speech item in question must, after generalization, no longer show specific definitions. In the case of pronouns, the gender border must ideally be crossed, and the meaning of the pronoun must be all-inclusive and none of the available genders or sexes may be excluded from the definition. In order to define an object by using a pronoun without too much specification, a generic term is used, which is then supposed to simplify the language for the speaker. However, in the case of English, the generic pronoun, which was incidentally chosen by male grammarians, is the third person singular masculine pronoun ${ }^{9}$. Instead of creating a new pronoun, a pronoun that has already assigned meaning has been developed over time and stated in a generic function in the language. That this enterprise must have opponents is obvious. In 1792, James 
Anderson, as cited by Dennis Baron (1986), suggests thirteen differentiations for gender in a perfect language.

To the traditional masculine, feminine, and neuter Anderson would add the indefinite gender, 'where the sex of the parties is either not known, or immaterial, and therefore not necessary to be known, or where it is wished to be concealed,' and the imperfect gender, useful both in countries where eunuchism prevails for purposes of insult. [...] and, finding the generic use of he inadequate because 'the effect is confined to the male, which ought to include the female,' Anderson would create a true common-gender pronoun to represent such indefinites as friend, servant and neighbor (Baron 1986, p. 96).

Deborah Cameron, in 1985, also points out the inadequacy of he as a generic pronoun and links this inadequacy to the markedness theory in grammar. She uses the generic he as an example for the first principle of markedness theory ${ }^{10}$ in which the generic has to be unmarked. For the generic pronoun he, "[...] this is an entirely circular claim: he is unmarked because it is generic, but it is generic because it is unmarked" (Cameron, 1985, p. 67). As we can see from this circle of argumentation, the reason for the generic pronoun as being the unmarked pronoun is rather unclear.

Another problem with the choice of he as the generic pronoun is its actual allinclusive meaning. In its primary function, namely as the masculine pronoun, it is recognized by every speaker in every situation, agrees in gender with its antecedent and can be accurately applied in sentences. But when it is used as the generic pronoun, it is supposed to lose this primary meaning, and suddenly to become allinclusive. The question in this case is that of condition, situation and environment. Where is he neutral? When does he not trigger thoughts or imagery of men? Various 
experiments (e.g. Cole, Hill, \& Dayley, 1983; Adamsky, 1981; Crawford and English, 1984; Connor and Serbin, 1978) the results showed that both children and adults produced much more imagery of males when encountering the masculine pronoun than imagery of females. Even if the situation was shared by both sexes, and it was not clear from the context that the person in question was either male or female, the generic he triggered pictures of males in the minds of the participants. If combined with the, allegedly, all-inclusive term man, he produced a clear male bias. Nevertheless, Cole, Hill and Dayley (1983) claim that the use of the generic pronoun he does not increase thoughts of men. Clearly being less sympathetic to the women's movement of the 1970 's, which started the debate about the pronoun use with the very influential book Language and the Women's Place by Robin Lakoff (1975), Cole, Hill and Dayley show through their studies that the equalitarian pronoun he/she does not lead to less masculine imagery than the generic pronoun he or the plural pronoun they do. They conducted five different experiments with men and women participating and evaluating neutral and stereotyped contexts.

Does the generic use of male pronouns give rise to thoughts of men? We found no empirical evidence to support the claim that, in and of itself, the generic pronoun gives rise to thoughts of men. Furthermore, the use of equalitarian pronouns did not increase the subjects' tendency to visualize women (Cole, Hill \& Dayley, 1983, p. 747).

But the connection of the generic he to the perhaps equally generic man, did in fact give rise to increased imagery of men. The remaining question stays the same: Can a pronoun that more frequently triggers thoughts of men be truly generic? 
In an experiment using children's literature and the reception of gender roles of the protagonists, Connor and Serbin (1978) found that stories which included masculine protagonists were favored by boys and girls, whereas stories with female protagonists received less positive reactions from the boys. Even the girls would rather be the masculine protagonist than the feminine one. It is not very surprising that the boys would rather be boys. In the context of the life of an eighth grader the interest in girls in a dating context is different. They no longer consider girls potential friends like fourth and sixth graders would, but start to see them more in a romantic light. The girls in this study showed basically the same preference for the male character as the boy's answers showed. This seems to indicate that the girls favor the active roles of the male characters in those stories more than that of the female characters. However, the experiment showed that boys are more sensitive to the sex of the main character of a story than girls are, and boys showed a greater rejection of stories about girls than girls did. (Connor and Serbin, 1978). Can this be an indicator of language bias and language use? It probably can be, and it would explain why the change of a pronoun in language use is such an obstacle. Language is acquired at a very early stage of child development. In this early age, connections and preferences are established and root themselves in the mind of the speaker. At this stage, the language learner learns primary meanings of words, and he has in its primary meaning the masculine pronoun and not the generic pronoun. It is therefore really no wonder that children do not see the generic function of this pronoun initially. This may change after formal instruction on the secondary meaning of he.

The term generic itself, however, can and should be further discussed. If we are talking about a pronoun that has been set as the all-inclusive, generic, unmarked 
pronoun, we have to move back in history and see that prescriptive grammarians formulated this pronoun as a language rule. Prescriptivism in grammar resulted in many language changes introduced by grammarians who thought that they had perfect language abilities and had the power to say in which way language would have to be used by the speakers. Unlike descriptive grammarians who describe the actual language use of the speakers, the prescriptivists set rules, which had to be obeyed by the speaker if they strove to speak the language 'correctly'. The prescriptive grammarians, however, decided that he would be the pronoun of choice when talking about 'mankind' in general, and thus ruled out using singular they, ${ }^{11}$ and proposed the meaning of he as he and/or she. In the further text of this thesis, I will therefore use the term generic he interchangeably with prescriptive he.

\subsection{Pronouns}

The problem with the generic use of male pronouns to refer to individuals of either sex is that such pronouns are too imprecise for scientific and legal discourse. [...] To use "men" to mean both "men" and "women and men" is an exercise in double think (Huber, 1976, p. 89).

Following grammatical rules for the structure of sentences in English, a pronoun must agree with its antecedent in gender as well as in number. This effectively means that we cannot conjoin a plural antecedent with a singular pronoun, (e.g. ${ }^{*}$ If students have an exam, he has to study a lot. ${ }^{12}$ ) or, the other way around, a singular antecedent with a plural pronoun (e.g. " If a student has an exam, they have to study a lot. ${ }^{13}$ ). Another constraint to the use of the pronoun is gender, in which case we must assign a masculine pronoun to a masculine antecedent, a feminine pronoun to a feminine antecedent and a generic pronoun to an unmarked antecedent. This, however, appears 
to be a problem in English. If the gender of the noun, or the biological sex of the antecedent is known, it is easy to apply the correct and appropriate pronoun. If the sex or gender is not known, rules of syntax dictate the use of the generic pronoun. For example:

a) The little girl ran after her puppy.

b) The three little girls ran after their three little brothers.

c) The little brother teased his little sister.

BUT d) The student had to do his homework.

Sentences a) - c) have a clear sex assignment for the subjects. Girl is a feminine word in English, and therefore receives she as the correct pronoun. The girls in sentence $b$ ) is plural and is referred to by the appropriate plural pronoun and The little brother in sentence c) receives the expected masculine pronoun. All possessive pronouns are assigned according to their precedents' gender. In sentence d) we see the problem. The student is a common gender or epicene word. It is all-inclusive for both male and female students and can therefore be used generically. From this sentence, we as the readers cannot say whether the student actually is a male student. The pronoun used, however, is the masculine pronoun. The sentence is grammatically correct, but semantically open to interpretation ${ }^{14}$.

Since English is a genderless language, the following sentences should also work with the use of the generic pronoun he.

e) The nurse cared for his patients.

f) The teacher counted his students.

g) The doctor filled out his charts. 
Nurse, teacher and doctor are professions that all deal with people. The nurse cares for the sick, the teacher teaches the young and the doctor cures the sick. But even though all three of these professions can be carried out by both men and women, the assignment of he to sentences e) and f) appears to be odd to the reader ${ }^{15}$. Sentence g) on the other hand, displays no problems with the use of the generic masculine. The profession of doctor or physician still seems to be rather male dominated ${ }^{16}$. If a woman were the doctor ${ }^{17}$, then this would probably already be pointed out with a certain specification for the doctor ${ }^{18}$. Ann Bodine (1975) claims in her essay on the generic pronoun he, that it promotes androcentrism in the language. This effectively means that it is no wonder that women are in worse positions than men, because language basically neglects and ignores them. She remarks that the grammarians choosing this particular pronoun promoted the position of men as superior in society, and that this choice "...was dictated by an androcentric world-view; linguistically, human beings were to be considered male unless proven otherwise" (Bodine, 1975, p. 133).

This rather strong position on the reasons for choosing he as the generic pronoun has to be supported by an analysis of the function of pronouns, and of the prescribed generic he in particular.

\subsubsection{Function of pronouns}

The problems already discussed with the use of he as the generic pronoun have caused some speakers of English to change their language use towards a different pronoun. When comparing the generic pronoun he in its prescribed function and the alternative pronoun they, which moves into the position of he, Donald MacKay gives a nice overview of the functions of prescriptive he and singular they. Next to the functions 
he also provides insightful example sentences. (See appendix $A$ for the full reproduction of MacKay's table.)

As functions for the prescribed generic MacKay lists the mixed-sex referent, the nonhuman reference, the unknown sex, the sex-concealed, the mixed-sex disjunctive and the deity function. Apart from the mixed-sex disjunctive function ("If either John or Mary comes, I will meet him at the airport."), the sentences and functions do not trigger a feeling of oddity in the reader. The mixed-sex function works in the mind of the reader, because it is in fact unclear which sex is predominant in the often times plural referent, so the choice of pronoun does not make a difference. For the non-human reference, Mackay gives the example of a fox tucking his tail between his legs. To my mind this is a bad choice, since the word fox clearly indicates that the animal is male. The female version would be a vixen, and saying that a vixen tucks his tail between his legs makes the sentence semantically wrong ${ }^{19}$.

The unknown sex of the referent also poses no problem to the speaker's language feeling when a masculine pronoun is applied, as does the sex concealed function. Interestingly MacKay mentions the deity function of the pronoun ("God manifests Himself in many ways." MacKay, 1980, p. 351). This use of the pronoun gives rise to a whole new discussion that could lead not only into religious understandings of the entity of God, but also into cultural semantics and may even question the whole notion of translatability of religious texts ${ }^{20}$.

In his second list, MacKay evaluates the use of the singular they. Leaving out the deity function, and replacing it by the corporate reference ("If Seattle calls, tell them I'm out.")(MacKay, 1980, p. 351), the sentences using the singular they in position of the generic masculine work much better in the reader's mind. 
Since pronouns are part of the closed class $^{21}$ of lexical items in the English language, it is almost impossible to just make up a new pronoun that will fit the various uses and functions of the generic pronoun already in place. Attempts have been made to replace the masculine pronoun with other, already existing, pronouns. In the next section, I will examine the application of those other pronouns in lieu of the generic masculine.

\subsection{He vs. She}

$\mathrm{He}$, as the third person singular masculine pronoun holds just this masculine connotation. It may take the position of a masculine antecedent inside the sentence. She, on the other hand is the feminine equivalent, and is posited in reference to a feminine noun. Unlike he, which may prescriptively be used as the generic pronoun, she is clearly sex-marked and any sentence that holds mixed-sex referents, sexconcealed referents or sex-unknown referents will be rendered feminine under the use of she. This seems to confirm the assertion that the only truly sex-marked pronoun is in fact she.

Semantics play a major role in all these connotations and assertions. In semantics, the categories work mostly in dichotomies. For the gender of a word, the semantic category gives the option of $[ \pm$ male]. This then means that a woman is $[-$ male] and a man [+male]. And yet again, a question appears: why is it that a man is always man, and a woman never man ${ }^{22}$. Why can't we say that a man is not woman? Is this how we really define the world around us? Can we only define woman by what man is? This leads back to the position of women in language and society. They are always connected to the men. Where would they be without them? 


\subsection{He vs. he/she}

$\mathrm{He} / \mathrm{she}$ is a special case in the discussion about the generic or prescriptive pronoun, since it has been around since the debate started. He/she appears as the equalitarian pronoun in the English language and has maintained the status of an accepted new pronoun for quite some time now in writing. Nevertheless, when the feminist movement started claiming its space in linguistics and brought the stone of sex-biased language into motion, most of the grammarians of English said that the use of he/she was clumsy.

Another variation of he/she was $s / h e$, indicating that the addition of the slash would not change either pronoun, and she would almost be visible as the leading pronoun. However, in spoken language, this orthographic device of sex-equality does not work, since it is impossible to say s/he.

In Words and Women (Miller and Swift, 1976), we can find an interesting and very reasonable suggestion for the change of the generic pronoun in English. Taking into consideration the primary meaning of he, the author suggests a different target group as the beneficiaries of language.

If women think it's important and men don't... let's use a pronoun that pleases women. Men don't care what it is as long as it's not clumsy so, from now on let's use 'she' to refer to the standard human being. The word 'she' includes 'he', so that would be fair (Miller \& Swift, 1976, p. 33).

This claim of using she as the generic seems very logical indeed. However, as we have seen above, she is the only pronoun in our already limited set of pronouns that is actually sex-marked in grammatical terms, so the use of it as a generic is prevented from the start, since it violates one of the principles of the theory of markedness; it is clearly not unmarked. 


\subsubsection{He vs he or she}

The contraction of he and she as in the above mentioned he/she or s/he originates from the phrase he or she, which, next to singular they, claims its place as an all-inclusive pronoun choice in everyday language use today. He or she includes both sexes and mentions them separately in one phrase. While a lot of effort was focussed on creating a new pronoun, or adapting different meanings for already existing pronouns, the allegedly awkward form he or she is now used without much ado. When returning to the origin of an epicene pronoun for English, we find the prescriptive grammarians advocating for the use of he as the generic and calling the phrase he or she too long, awkward, cumbersome, and not elegant enough (Baron, 1985). This sentiment toward the pronoun phrase is somewhat forgotten today, as style manuals for publications suggest the use of he or she instead of the generic pronoun he. The use should, however, be applied sparingly, because the repetition of he or she can become tiring. Instead of using pronouns, sentences should be rewritten so avoid the use of pronouns altogether, or to create plurals so that they may be used as the unmarked pronoun (APA, 1994).

\subsection{He vs. they}

The difference between he and they appears at first sight more like a discussion of singular vs. plural. English as a genderless language relies heavily on the distinction between singular and plural. Pronouns and antecedents have to agree in number, since the gender is largely undefined. Seeing the situation from the point of view of generic usage, they can be applied in many situations, where he implies a certain masculine connotation. Bodine (1975) claims that prescriptive he and singular they are 
linguistically equivalent alternatives, and Miller and Swift (1976) even predict that they will become the generic pronoun in the future of English, but other researchers find little or no reason to subscribe to these view points. They behaves neutrally with regard to sex for all antecedents in the sentence. He, in contrast, is never neutral and is generally used to reference neutral and predominantly male antecedents (MacKay, 1980). It also appears more natural in connection to indefinite pronouns such as everyone, nobody and the like because of its agreement in number. He does, however, create some ambiguity, especially if the generic use is not well known to the speakers or is deliberately ignored by speakers.

Mackay found a major problem with using singular they as a generic in the field of its connotation, since most speakers tended to feel detached and lose the personal involvement and meaningfulness in the sentence. One of the many applications of they is that of the pronoun for a mass of inanimate nouns. Since this use is common, the application in a sentence with animate antecedents may in fact create a certain awkwardness and detachment from the animate antecedent (MacKay 1980). "Pluralization in general weakens a sentence, making it more difficult to imagine and remember" (MacKay, 1980, p. 358).

\subsection{She vs. they}

The discussion about the singular feminine pronoun and the plural pronoun as generic is actually rather pointless, because she as a generic cannot be discussed for its already mentioned semantic load for the sex of the noun. However, in a study done by Catheryn Adamsky, it was shown that women report feelings of importance, power and superiority when the use of the prescriptive he was changed to she. This feeling of importance and actual inclusion in the topic triggers an elevated rate of memory effect. 
This could in fact mean that if all-girl schools used schoolbooks, which consistently used she as the generic pronoun in their texts, the learning effect of the girls could be much higher. Just as the singular they distances the reader personally from the action, the generic he distances girls from the action in the text, because they think of themselves in terms of she and not he. However, since all girl schools are very rare, and the educational trend moves towards complete co-educational schools and universities, the picture and necessity of using she as a generic in schoolbooks is probably more imaginative than factual and reasonable.

\subsection{Sex vs. Gender}

The distinction between "sex" and "gender" essentially recognizes biological and sociocultural differences. The biology of masculinity and feminity -that is sex differences- begins to differentiate prenatally... the sociology of masculinity and feminity - gender - differentiates postnatally. (Chambers, 1995, p. 103).

Sex and gender are two important terms that need to be looked at from many different perspectives because of their immense semantic load. In the next section I will explore their implications and functions in two areas; that of language and the science of language, linguistics, and that of the sociological background of sex and gender, and its impact on speakers of English.

\subsubsection{Sex vs. Gender within language and linguistics}

Sex and gender within a language has to be regarded from two different standpoints. The first is the biological sex of the speaker of a language. This influences language in many different ways. The differences between male and female speakers start in the pitch and intonation of words and go all the way to a small set of different vocabulary 
and different language uses. Sociolinguists like Deborah Tannen (1990) talk about different languages between men and women and the term 'genderlect' was coined in order to visualize the differences in language ${ }^{23}$.

The different use of language for men and women shows different reasons for speaking in general. It is claimed that men speak for 'report' reasons, whereas women speak for 'rapport' reasons. This would indicate that men speak less than women. Apart from this being a constantly reinforced stereotype about women ${ }^{24}$, this assumption strikes me as odd when looking at the prescribed pronoun. Why is it, if women use language more often that the prescribed generic pronoun they use has to be the masculine third person singular pronoun? Would it not make much more sense to say that the more frequent users of a language should be the more frequently displayed users, meaning that we should use the feminine pronoun rather than the masculine pronoun? The problem seems to be that the prescriptive grammarians of the past were male and thus created language rules in a way that Bodine describes as androcentric. Men are the major influence on language change because they were able to set the rules of language use. It is interesting, nevertheless, to note at this point the alleged power of the prescriptive grammarians. Their rules were in fact obeyed by the speech community and their changes were therefore implemented into the language.

The other way we need to look at gender and sex in language is the linguistic meaning that is quite separate from the social or biological meaning. Gender is expressed in language mainly through inflectional affixes on nouns and changes of articles and agreement of other parts of speech. Gender categories in language feminine, masculine and neuter - are only loosely connected to the real world. This arbitrariness may cause some frustration in the language learner, but it should be 
avoided to 'translate' grammatical gender as masculine=male, feminine=female and neuter=sexless. "Although English is now primarily natural, the rule of the generic masculine shows that nonreferential gender still exists" (Baron, 1986, p. 110). 'Nonreferential' means in this case that objects are assigned gender that is not necessarily connected to the real world (what is masculine about a table/truck/student of linguistics?), but that the generic pronoun is in a position to assign the gender to the object. Personifications of inanimate objects should logically call for a neuter pronoun, but examples like sea, ship, city and tree in English show us differently. Their gender assignment can be traced back to cultural ideas that prescribe gender. Compound nouns like mailman, policeman ${ }^{25}$ and so forth contain the affix -man, which, just like the generic he are mere signs of genericity. But in connection with an appropriate pronoun, the masculine pronoun is chosen, thus making the female portion of workers in the above fields invisible. Open sex-marking of nouns often results in affixing of -ess, -ette and -ine, which makes English appear as a sexually biased language, because it is only the female population of English speaking countries that need affixation to become visible in language.

In linguistics, gender roles and sex roles are often discussed under the heading of sex roles. However, in this thesis, I will try to treat gender and sex as independent influences on language. I do this because I believe that the gender of a speaker can be changed, whereas the biological sex, which may also be changed through operation, remains the same in the DNA of the speaker. There are also many examples of genderbending, but this discussion would lead too far away from the point of this thesis. 
The discussion, however, is meant to show that not only the biological differences apply to language, but also that the social differences, the different genders, play a role in the discussion, and both are actually tightly interwoven.

\subsubsection{Sex vs. Gender outside of language and linguistics}

The discussion of sex and gender outside of language and linguistics is actually bound to lead us away from linguistics and into biology, literary theory and social studies. In today's day and age, discussions about social roles for men and women tend to border on sexual bias and stereotypes. Whereas stereotypes are an important psychological feature of the human mind, the only thing that, at this point in time, can be said about the role of a woman, that cannot under any circumstances be performed by a man, is that of giving birth to a child. On the other hand the only "profession" that only a man can hold and a woman never can is that of the sperm donor. But even construction work, which used to be a male-only profession, has turned into work women are capable of and will be hired for (Chambers, 1980.).

An interesting loop back into linguistics could probably be the tie to transsexuals, who experience being in the realm of the incorrect gender. A man who wants to be a woman, but shows all the genitalia and the DNA that make him a man, might in fact use language in a "feminine" way. This definition of the language this person uses then calls for another dichotomy in which it seems mandatory for women to acquire a masculine way of speaking in order not to be discriminated against anymore and to be equal to men. But it also seems as if biological sex in general and the female sex in particular become less and less a problem of oppression and retraction in everyday life. Feminists and the political correctness movement have accomplished a lot. Being a woman no longer means that one is a subgroup of human beings and that men are superior. The 
fact that this thesis is written shows that women and men are aware of the functions of language and of their ability as speakers of language to change the language and use it wisely. However, sex and gender outside of language shall not concern me more at this point. As mentioned before, literary theory, gender studies, and biology probably have more space for discussions of this kind. 


\subsection{History of generic pronouns}

This section of my thesis deals with the historical development of the generic pronoun in English. The history of the development of a generic pronoun in English can probably be traced to the beginnings of the language. Every speech act that describes the action of another human being without stating the proper name or a full reference for the agent requires personal pronouns. If the gender of the agent is concealed in any way, the applied pronouns have to be generic and all-inclusive as to include both male and female participants in the action. Pronouns, as words which specify the noun have to be detailed enough to give a sufficient reference to the agent of the action, but they must also be general enough as to leave room for some interpretation.

Which theory about gender assignment in language was eventually followed is unknown. What is known, however, is that Indo-European languages acquired genders which were, according to Aristotle assigned by the Greek grammarian Protagoras, who wanted to describe life and truth through language. These genders are masculine, feminine and neuter. Their specification emphasizes the sexual division of the world, but, as mentioned before, the gender assignment of nouns is not always strictly connected to the biological sex of the referent.

English lost grammatical gender in the Middle Ages, in the transition from Old English to Middle English. This loss probably resulted in somewhat of an improvement of the language and made speech in both its use and acquisition easier, in at least this area of grammar. And as many learners of English as a foreign language can say from experience, this loss of yet another peculiarity of the language makes the learning of English easier than the learning of languages like French or German, which, in addition 
to the grammatical gender, also affix case endings to their nouns and adjectives, which may be different for every gender. The loss of gender in English reduced the inflectional morphemes down to eight, thus taking sex marking out of nouns and adjectives. The set of pronouns, however, stayed pretty much the same. Only the dual number for pronouns disappeared in Middle English. Case was still present at that time. Pyles and Algeo give a comprehensive overview on the development of the English language and state numerous examples of the change from Old English to Middle English in The Origins and Development of the English Language. (See Appendix B for a list of pronouns.) As we can see in the table, the singular pronouns are given including case endings for $1^{\text {st }}, 2^{\text {nd }}$, and $3^{\text {rd }}$ person. In the plural we also find the same patterns. Apart from individual case endings the pronouns in Middle English, except for the $2^{\text {nd }}$ person singular, are very much alike our pronouns today.

Eventually in the course of the development of the English language, the need for a generic pronoun had to be encoded into the grammatical rules for English. It appears as if initially the generic pronoun for both singular and plural antecedents was in fact they and not he. ${ }^{26}$ Why the masculine pronoun was chosen to be the generic pronoun has many different reasons, all of which appear slightly male biased. The discussion still prevails today, with its points of argument staying intact. And while the supporters of the masculine generic pronoun he say that it does not exclude women from its range of meanings, these very same supporters reject the possibility of a generic, unmarked use of a feminine pronoun because a feminine pronoun would exclude men. This appears as just another circular argumentation line in favor for the generic, unmarked use of the masculine pronoun. The connotation of the pronoun is supposed to be generic, but at the same time it is not, and cannot be conceived to be generic and is not an acceptable 
solution to speakers whose consciousness is raised. In a time when schoolteachers were predominantly female, the National Education Association (NEA) changed their use of generic pronouns from he to she. Even though most of the teachers at that time were in fact female and the male teachers should have been aware of the generic meaning of he, the NEA took the complaint of a male teacher about his feelings of being left out and of his being underpaid in general, seriously and changed its statutes back to the application of the third person singular masculine instead of the feminine. The claim that a generically used feminine pronoun would give the profession of teaching a negative connotation should have struck the members of the NEA as odd, but they apparently did not feel the need to change the connotation of the profession and of men in this profession in particular, but rather changed the pronoun. In regard to language awareness, I believe that this move tells a lot about the position of women and everything that is connected to women in language. If the application of a masculine pronoun in sentences supposedly does not trigger imagery of males, but, again, supposedly, appears generic and all-inclusive, why are there so many male opponents to pronoun change? Is it because the association of a feminine pronoun with a group of people may let the men in this group to appear effeminate ${ }^{27}$ and possible as homosexuals? A possible answer may be the fact that male images in figures of speech precede female images (e.g. Adam and Eve, man and woman, husband and wife, etc.) and that speakers thus feel that it is just to use the masculine pronoun as a generic, even if the majority of the people talked about may in fact be female.

Another possibility is in fact the influence of prescriptive grammarians on the speakers of a language. These grammarians decided at some point to promote the masculine pronoun as the generic and prescribed language use for generations of 
speakers. Today prescriptivists and language purists still defend the notion of the generic he in English, and voice their complaints about the change of pronouns towards are more equalitarian pronoun. The next section will deal with some of these grammarians and their influences on the usage of English.

\subsection{The 18th century grammarians}

The $18^{\text {th }}$ century brought forth many very influential prescriptive grammarians. These grammarians, almost all of whom were men, rewrote already existing language and grammar rules, evaluated them, compared them to their functionality and efficiency in relation to other rules of the language and then formulated prescriptive grammar books. These prescriptive grammar books then influenced the speakers of the language in a way that made them reconsider rules they had already learned and used and made them substitute these common rules with the newly stated rules by the grammarians. The justification for some of those rules were sometimes taken too far off and were mostly rooted in other disciplines like religion and philosophy, or sometimes even the feeling for the language of the writer.

Thomas Wilson, who has to be considered one of the first prescriptive grammarians to influence the generic pronoun debate, argued for an androcentric order in language in 1560. And even though this is long before the eighteenth century, he has to be considered the leader of those grammarians in the eighteenth century. His views were very influential and must be considered a starting point of the change of language by the prescriptivists.

Some will set the Carte before the horse, as thus. My mother and my father are both at home, even as thoughe the good man of the house ware no breaches, or that the graye Mare were the better Horse. And what thoughe it often so 
happeneth (God wotte the more pitte) yet in speaking at the least, let us kepe a natural order, and set the man before the woman for maners Sake (Wilson 1560 in Bodine, 1975, p. 134).

Wilson does not really come across like someone who is in favor of women's rights but rather like a misogynist. He is of the opinion that it is appropriate to name the man first and then the woman. This view carried over into the $17^{\text {th }}$ century, when Josua Poole wrote: "The Relative shall agree in gender with the Antecedent of the more worthy gender: as, the King and Queen whom I honor. The Masculine gender is more worthy than the Feminine" (Poole 1646 in Bodine 1975, p. 134). Why exactly the feminine gender is less worthy than the masculine or why the queen is less worthy than the king does not become very clear from his statement. The relation between kings and queens at that day and age can possibly be compared to today's political leaders and their wives. Even today we sometimes question who has more influence on the other. But at the same time a couple is probably more apt to rule successfully when working together than when working alone. Even Virginia Woolf claims in her essay A Room of One's Own, that only the androgynous writer, the writer that combines both male and female characteristics in their writing can be considered the successful writer. Only both parts, male and female, can make for a wholesome creation of writing. If writing is biased towards the male aspect, women will be displeased with it, and if it tends toward the other side, men will think the work to be effeminate. Woolf's thoughts make a lot of sense, and why should this androgynous thinking not apply to successful rulers? The differentiation given by Wilson and Poole explains, however, why so many coordinate structures start with the male object and not the female object. 
These examples of masculine superiority do not contain any information about the use of generic pronouns yet. In 1746, another prescriptive grammarian named Kirby presented 88 rules for the correct syntax in English. One of his rules included information about the generic pronoun. He does not call it worthier anymore, but describes it as more comprehensive than other pronouns. "The masculine Person answers to the general Name, which comprehends both Male and Female; as Any Person, who knows what he says" (Kirby, 1746 in Bodine: 135). The general name, the full noun, is thus assumed to be masculine in the first place, and in second position maybe feminine, since the generic pronoun used to describe this noun is the masculine pronoun. Exactly why the masculine is more comprehensive - no explanation at this point. I can only assume that he concluded this from his own sex and maybe his position in society, scholarship and possibly his own family. Maybe the masculine pronoun in his mind even did include women. Maybe he thought that by using this pronoun he would do womankind the favor of not singling them out anymore. Maybe he wanted to save space and avoid writing he or she. Or maybe he was just another misogynist who was convinced that the female sex is less comprehensive, or less worthy, than the male sex. These can only be assumptions as Kirby never wrote any further justification of his pronoun choice or gave more reason than that mentioned.

Another eighteenth-century grammarian saw no reason for having an unmarked gender. " ... he must represent a male; she a female; and it, an object of no sex... But the plural they equally represents objects of all the three genders" (Ward 1765 in Bodine 1975). Not only did he reject the idea of using the masculine as the unmarked gender, he also promotes they as the unmarked pronoun, since it can include masculine, feminine and neuter objects in itself. 
In 1795, Lindley Murray places another swing against the use of singular they. In his opinion it is mandatory for the antecedent to agree with the pronoun in number, gender and person. Connections of anyone with they were ruled out as ungrammatical since anyone clearly states its singularity while they is a plural pronoun. By 1850 , these rules had made it to the Act of Parliament, which held as the all-inclusive pronoun he and she up to that point. For legal purposes, he and she was then replaced by he as the generic pronoun.

An Act for shortening the language used in acts of Parliament...in all acts words importing the masculine gender shall be deemed and taken to include females, and singular to include the plural, and the plural the singular, unless the contrary as to gender and number is expressly provided (cited in Bodine 1975, 136).

From this statement, it seemed plain to understand not only men but also women to be present in statements using the new generic pronoun. History shows us quite the contrary behavior and treatment of women though. Not only were women not allowed to vote, as they weren't before either, or to receive higher education, or to own land or to conduct many legal situations, they were also conceived of as the inferior sex. With the newly rewritten statements and laws about the rights of man, which is another generic term excluding women by primary meaning, women should be included, and be granted the same rights as men, but this was not the case, since not the secondary, namely generic meaning of the pronoun was seen, but in fact the primary, the masculine meaning. Men were the legal persons in the household, responsible for all financial matters, since laws were now explicitly written in favor of males, using a masculine pronoun. Miller and Swift's (1976) naïve question returns: Where is he neutral? 


\subsection{Generic pronoun variations ${ }^{28}$}

This section is devoted to the historical changes of the generic pronoun and the many attempts to create a new pronoun that is not already laden with meaning but may be a fresh start in the quest for an all-inclusive pronoun. Dennis Baron in his book Grammar and Gender (1986) gives a comprehensive list of pronoun variations. All the pronouns in his list are inventions of concerned linguists, or of people who were not linguists by profession but who cared about language and semantics. In this list we can see that the first innovative pronouns that made it to publication around 1850 were ne, nis, nim and hiser. The similarity to he, his, him and his or her is still visible, but since the first letter in each pronoun has been changed, the connotation has been taken off the word. They are harder to recognize as variations of the traditional pronouns, and the new versions will therefore have to create their own mental images in the speakers' minds. Out of these new variations of pronouns especially hiser returns frequently in the history of the pronoun. We can find it in 1884, 1891 (with different spelling, and slightly different pronunciation: hizer), 1912 (his'er), 1927 (hizzer), 1975, 1978 (hizer), and 1984. An interesting and very reasonable proposal is that of Charles Crozat Converse's thon, which appeared in 1884 (a rather busy year for pronoun inventions). Converse created thon as an abbreviation of the one or that one. One being generic and allinclusive anyway appears as the most attractive choice for a pronoun position. It has, however, not been accepted as a generic pronoun, and I assume that Converse created thon to propose a pronoun with a more specific connotation than one has by itself. Adding the abbreviated article in thon, this pronoun can truly point to a certain subject or object and create a difference between it and another pronoun. Lillian Carlton used one as a suggestion for a new generic pronoun in 1979. However, as we can see from 
further ideas about new pronouns, linguists tended more towards a combination pronoun of he and she, or their possessive forms his and her, than actually creating something completely different.

Dennis Baron recounts an interesting story on the creation of a new pronoun in which the head of the National Education Association Ella Young created a new pronoun in 1912. In her creation she added the regular feminine pronoun ending -er to the already existing masculine pronouns and came up with he'er, his'er and him'er. These constructions made a lot of sense to her and to her understanding of a generic pronoun. Her pronoun construction reminds one of the construction of feminine forms of already existing nouns, in which suffixes are added to the noun to make them feminine. It is interesting to observe that most wordsmiths or neologists often base their pronoun creation on the masculine pronoun and not, which would appear as more logical, on the neuter pronoun it. And also, as we can see from the list of publication dates for hiser, the neologists were not particularly aware of their predecessors. Otherwise there is no explanation for the redundancy in creation. The given explanation for the individual pronouns, however, are complex, and also worth looking at.

The masculine part of most masculine-feminine blends precedes, just like in the above-mentioned figures of speech, the feminine part. This order is sometimes reversed, but even in those cases, the pronoun is declined in the masculine pattern. So there will be hiser, him'er (1912), hires (1979), but also the feminine pronoun part first sis (1938), heris (1970) or shim $(1934,1972)$. Some combinations are the feminine pronoun and a plural pronoun (e.g., shey, sheir, sheirs, 1979, shey, shem, shir 1982). One suggestion is actually she, demonstrating the feminine pronoun 'embracing' the masculine one. 
Unique coinages are in fact only thon, ip (1884), co (1970), fm (1972), po, xe, jhe (1977), ae (1978), and per (1972). Of these unique ideas, some are not pronounceable, making them rather pointless for actual language use. The wordsmiths for these pronouns must have only considered writing as a means of communicating equality in pronoun matters. This may actually make a lot of sense, since the use of generic pronouns may in fact be more in written language than in spoken language. In spoken language the interlocutors usually know the biological sex of the subject they are talking about and can therefore apply the correct pronoun. But even in spoken language there will be instances of unknown gender, and in those cases a pronoun creation which may actually be pronounced would be much more helpful than one that is not pronounceable.

Miller and Swift (1976) report the failed case of new pronoun inclusion of a student newspaper in Tennessee. The Daily Beacon decided to try out the common gender pronouns tey, ter and tem for a limited time of eight months. After three months, the experiment was dropped because readers misinterpreted, misunderstood and massively ridiculed the newspaper. When Reuter's new agency distributed the news of a student paper abolishing gendered pronouns and the critique inside the university grew more and more tense, the editors decided to give up the experiment, thus making it a failure. This happened in 1973 (Miller and Swift, 1976, p. 132), almost thirty years ago. At this point, feminism was not an entirely new movement anymore, but very much in the limelight of the news and in the awareness of people all over the United States and especially on university campuses. The attempt to implement a new pronoun in order to provide gender equality in a student newspaper has to be considered a very brave endeavor. At the same time, it could have been just this brevity of the editors that 
pushed the issue of so many feminists yet again into the faces of readers, that further affairs involving emancipation and gender equality plain and simple pushed the limit of patience and acknowledgment of society over the edge. It is a pity that the Daily Beacon failed so rapidly and completely in its effort. Nevertheless, I am sure that the fact of the editors using tey, ter and tem instead of the common masculine generic pronoun called the primary meaning of the generic masculine pronoun to the attention of the readers. This raising of language awareness in the readers is probably at the time of the pronoun - experiment's failure the success of the language change intent. 


\subsection{Language and Culture}

In this chapter I will comment on the relationship between language and culture. This relationship is a very important one as language and culture define our everyday lives to a large extent. Every human being has the ability to produce and use language, and will do so in every case. The language ability in the human being has to be exercised, given all physical prerequisites are intact. Culture is omnipresent around us. The ways in which language, culture and thought interact have been questioned again and again in the last few centuries, and it seems as if no one can give a sufficient answer to the problem of their definition. It seems reasonable to me that language may in fact influence the culture of its speakers. In this chapter of my thesis I will talk about the (in)famous Sapir-Whorf hypothesis, the influence of anthropology on linguistics and vice versa, and will then lead over to the next chapter in which I will examine the feminist understanding of the hypothesis and its implications for the position of woman in language.

Both terms language and culture call for further definition, and both are either very basically and easily defined as systems of slightly different kinds, or their definition might turn out to be a very complicated task. Language, on the one hand, is a system of communication and culture is a system people live in. Language and culture, on the other hand, may appear too complex to even start a definition. In my own understanding, both language and culture have many different, independent but still interconnected subcategories. On account of all these subcategories, a general split of these terms is almost called for and a restructuring of the definitions is necessary. Both language and culture cover so many different things in their definitions that the use of 
these extremely broad terms may be confusing. Language is indeed a system of communication, but culture may be called by the same name ${ }^{29}$ but it also defines its speaker, while the speaker defines and changes the language they use constantly. ${ }^{30}$ At the same time culture is defined by the people living in it while culture also influences and defines 'its' people. Since both terms are so tricky and complex in and of themselves, I think I must limit myself at this point to an attempt of a definition in order not to confuse myself or my readers in my further proceedings.

With language, I mean a system of communication that defines its speakers by a certain given set of vocabulary and certain, conventionally agreed upon structures. The way the speakers use this language alters the language in individual ways and makes it unique for every speaker. At the same time we have to be aware that all speakers start to use this language under the same conditions, namely with the same set of vocabulary.

My own definition of culture is closely connected to language. There is no language without culture and no culture without language. The speakers of a language are united in culture, and at the same time define their culture by being in it. This is not to mean that language is just another cultural trait and can only exist in one culture at a time (which is easily proven incorrect, as English is spoken in America and in England, and the cultures in these two countries are as a matter of fact very different), but that language is connected to and supported by culture. All people in a culture have the same conditions to start from and will be part of a larger group by their actions, namely their culture. And I believe that it is much easier to change one's language than one's culture. Culture penetrates the self and the experience of the self much deeper than language does. Language is, in my understanding, a means of expression for the 
experience. Experiences are different for everyone, since they are interpreted on all levels, most of them subjective. We can relate this interpretation of experience to immigrants, who mostly have to acquire language and cultural traits of the country they move to at the same time. Their cultural and language behavior is different from that of native speakers of people born in the culture in question. The relationship between the immigrant and the new language may be very difficult, since some languages clearly lack the vocabulary to express the interpretations of experiences correctly. So even if the language can be mastered in a foreign country, the assimilation to the new culture is a complicated task. ${ }^{31}$ The question is whether culture now influences language or whether language influences culture.

Since this is only my definition, I will now look at some of the more influential people when it comes to the relation of language and culture. Anthropology has always had, on some level, to deal with language and the meaning and connotation of it for the people. Different civilizations had different languages, some had elaborate communication systems and were able to prosper and survive, others, with a less strong language, were conquered by those with a powerful language ${ }^{32}$. Languages always played a role in power relationships among humankind and are therefore of interest for linguists, anthropologists and even political historians. In my next section I will focus on anthropology and its connection to linguistics.

\subsection{Sapir and Whorf - Anthropology and Linguistics}

Edward Sapir studied American Indian languages at Columbia University where he was strongly influenced by Franz Boas. Boas was a dominant figure in establishing modern anthropology in the US. Edward Sapir eventually started a new branch of linguistics which he called Ethnolinguistics. In ethnolinguistics the interrelation between 
language and cultural behavior of those who speak it is studied. Benjamin Lee Whorf was a disciple of Sapir. Not being a trained linguist, but rather an insurance investigator, Whorf eventually studied American Indian languages, especially Hopi, and deducted that the language spoken influenced the cultural behavior of its speakers massively (Whorf, 1956). ${ }^{33}$

Both Sapir and Whorf were in close contact and studied the German philosophers Herder and Humboldt. These philosophers believed that the language people speak will have some bearing on their perception of their world. The idea that language influences culture has become known as the Sapir-Whorf hypothesis. ${ }^{34}$ The value of this hypothesis for anthropology is not to be underestimated.

[M]any anthropologists have always been sensitive to the importance of language in regulating society [...] Some anthropological linguists believed that the extreme variations they observed in different people's perceptions of reality were directly attributable to language (Cameron, 1985, p. 22).

Naturally there are many studies that disprove the validity of the hypothesis, but as we will see in the next section, even these studies can only disprove a certain aspect of the hypothesis and not the claim in its completeness.

\subsection{The Sapir - Whorf Hypothesis}

The Sapir - Whorf hypothesis actually exists in two versions. In literature they are generally called the strong and the weak version of the hypothesis. I, however, agree with Janet Bing on the assertion that the fact that one is called the weak version makes it appear as if it is less important than the strong version (Bing, 1991), and will call them the extreme and the moderate version. As mentioned before, many studies have been 
done to prove or disprove the hypothesis, and any sort of failure can only be assigned to the extreme version, and not the moderate one.

The extreme version of the hypothesis is also known as linguistic determinism. Since the hypothesis claims that language and culture influence each other, the extreme version would claim that, for example, certain words for a color in a language will let the speaker only see this color in accordance with the words they have in their vocabulary. This implies that language may actually change the physical attributes of the speakers' eye in order to let them see only certain colors, or certain shades of color.

For instance, if one race of people had the physiological defect of being able to see only the color blue, they would hardly be able to formulate the rule that they saw only blue. The term blue would convey no meaning to them, their language would lack color terms, and their words denoting their various sensations of blue would answer to, and translate, our words 'light, dark, white, black,' and so on, not our word 'blue' (Whorf, 1956, p. 209).

This thesis clearly is too extreme a claim, since language cannot be the reason for a change of anatomy. This version also has been disproved. Color terms are in fact an often-studied matter when it comes to the Sapir - Whorf hypothesis, since color terms can be objectively judged without influence from ideologies or beliefs.

The moderate version of the hypothesis declares that objective reality is perceived differently by different cultures or in different circumstances according to the language spoken. In Edward Sapir's words:

[Language] powerfully conditions all our thinking about social problems and processes. Human beings do not live in the objective world alone, nor alone in the world of social activity as ordinarily understood, but are very much at the 
mercy of the particular language which has become the medium of expression for their society. It is quite an illusion to imagine that one adjusts to reality essentially without the use of language and that language is merely an incidental means of solving specific problems of communication or reflection. The fact of the matter is that the 'real world' is to a large extent unconsciously built up on the language habits of the group (Sapir, 1966, p. 66-7).

Sapir's notion is that of linguistic relativity. Sapir elaborated on the idea of language influencing culture, but Whorf took these ideas further in his studies of Hopi and created the notion of linguistic determinism. He implemented this theory of relativity into a connection with the understanding of nature, the basis to the differences in many cultures.

We dissect nature along lines laid down by our native languages. The categories and types that we isolate from the world of phenomena we do not find there because they stare every observer in the face; on the contrary, the world is presented in a kaleidoscopic flux of impressions which has to be organized by our minds - and this means largely by the linguistic systems in our minds (Whorf, 1956, p. 213.).

For him, language is inseparably connected with the mind/brain of the speaker and with culture and the understanding and interpretation of the world around us. The main focus of his studies was Hopi, an American Indian language. In his studies of Hopi, he found no vocabulary items for time and no verb tenses, as we know them in English. He therefore concluded that the Hopi understanding of time is so radically different from that of English speakers, or even speakers of Standard Average European, which was his umbrella language terminology for European languages in the western world, that it 
is no wonder that speakers of Hopi come into conflict with things like bus schedules. By coining the term Standard Average European, Whorf also implied that the European cultures shared the same worldview. His reason to study Hopi was, among other things, that he believed this culture to be radically different from that of English speakers. His findings showed him that Hopi in fact is a gendered language. This astounded him so much, that he implied a worldview to Hopi, which put nouns into genders and declined adjectives according to the nouns, and thus was completely different from the culture and worldview of an English speaker. The genders he found in Hopi are not necessarily the genders we find in European languages, where gender is assigned on grounds of biological sex, but genders in Hopi adhere more to the Greek definition of gender which may be translated as kind. Nouns in Hopi are divided in animate and inanimate nouns, but this kind of division is basically the same division languages like French, German and Italian apply to their nouns, only that they are based on somewhat biological differences. And what Whorf failed to see, probably because he had already subsumed other languages spoken in Europe under Standard Average European was that French, German and Italian are also gendered languages.

In fact, the various contrasts in world-view for which Whorf argues differ greatly in the extent to which they are surprising or controversial. Boas had already made the point that, for instance, where English has the one word snow Eskimo has separate basic roots for snow falling, snow on the ground, drifting snow, and so forth; at this relatively concrete level disparities between the conceptual schemes of different languages are fairly familiar, and there is no doubt that they influence perception - it can be shown that people's perceptions of their surroundings are modified by the conceptual categories their language 
happens to provide. Whorf discusses cases of this kind, but they are not what he is primarily interested in. 'What surprises most', Whorf rightly says, 'is to find that various grand generalizations of the Western world, such as time, velocity and matter, are not essential to the construction of a consistent picture of the universe' (Sampson, 1980, p. 86)

When talking about the grand generalizations of the Western world, Whorf makes just this, generalizations. The problem with this is that they are only seldom correct, and that even within Europe notions of time and velocity are very different. Sampson criticizes Whorf's notion of the over and covert marking of nouns in Hopi.

The way I see the Sapir - Whorf hypothesis is very close to the term itself. It is a hypothesis and should be treated as such. I agree with Miller and Swift (1980) when they say that "[w]e are better at coping with things, whether they involve inanimate nature or human relationships, when we have names for them than when they are nameless or their names are inadequate" (Miller and Swift, 1980, p. 141). Vocabulary is a major influence on the way we express ourselves. If words are not to be found in our language, we cannot name things properly. By this I mean that especially language learners or speakers of other languages may find it hard to express their thoughts if words are lacking to give detailed descriptions. This is not to say that some languages are better than others, since this can not be a valid linguist statement. But if some words, such as the masculine pronoun are more frequent than others, we will apply the meaning assigned to the words more often than others. If Hopi can be called a timeless language, because of a lack of time adverbials, tense forms and other vocabulary items, a close look at English with regard to androcentrism is called for. Hopi is timeless and English is androcentric. As mentioned earlier, one of the principles of the markedness 
theory is the frequency of the unmarked term as opposed to the marked term. He was chosen to be unmarked because of its generic meaning, and it received the generic meaning because it is unmarked. Since it holds the position of the generic unmarked pronoun, its frequency is much higher than that of the feminine pronoun in a generic sense. If we believe the Sapir - Whorf hypothesis to the extent that the language we use and hear influences our perception of the world surrounding us, then we have to conclude that the world around us is largely masculine, unless proven otherwise. This proves the androcentrism claim of Bodine. English can be called an androcentric language because of the generic pronoun choice. Feminists, however, usually don't leave it by this definition of the characteristics of language, but take it a step further. English, in the mind of many feminists in linguistics is a sexist or sex-biased language. I will get to this point in section 4.1. of my thesis, but I would like to link this assertion to the Sapir - Whorf hypothesis at this point. I believe that the claim of androcentricity may in fact be true for English, the reason being the generic pronoun he. Since he in English has two meanings, one that of masculinity and the other that of the unmarked, sex indifferent, generic pronoun, it may easily be concluded that the masculinity is the primary meaning, implying that there are more men than women around in English.

But sex bias per se is something that can only be attributed to the speakers of a language, and not to language itself. Language cannot be seen as a living thing, which carries out certain implication on its own. It must be seen as a tool for communication for the speakers. The speakers then may change the meaning of the words they use, and they may also adjust the frequency of words used in their language to a level where the meaning of the word in question actually changes, but we cannot say that a 
language can be sex-biased. I believe that there is a fine line between androcentrism and sex-bias, and I hope to make this line a little clearer in my next chapter. 


\subsection{Feminism and Linguistics}

Feminism and the women's movement have had major impacts on many formerly male dominated academic disciplines (Spender, 1981). The reason for this interest in academic disciplines that have been around for a long time is the imbalance of men and women especially in academic departments at universities or other educational or research institutions. Knowledge is traditionally connected to the research done by men and academic disciplines can in fact be called men's studies. The emergence of women's studies departments at universities serves as evidence for the necessity of separation of male and female interests in academia. Women's studies departments do not exclusively teach about female issues, but rather provide the room and opportunity for women to learn, teach and engage in discourse about both 'male and female studies'.

Women traditionally appear in smaller numbers than men in science departments. This is traditionally blamed on the incapability of women to deal with technology or even mathematical equations. These are stereotypes that seem to prevail in society and are hard to overcome as women in physics or engineering departments all over the world may agree on.

Fundamental to feminism is the premise that women have been 'left out' of codified knowledge; where men have formulated explanations in relation to themselves, they have generally either rendered women invisible or classified them as deviant (Spender, 1981, p. 2).

With the number of men in academic departments in research institutions being much bigger than that of women, it is no wonder that the situation of women is that of 
deviation. Subjects are male unless proven otherwise or needed otherwise. If subjects are female then their use is usually that of providing the other, the less obvious side to a study. The male value seems to be much higher than the female value.

Feminists are people who fight for the equal treatment of women in every aspect of society. For the field of linguistics this means that linguists at some point started to pay special attention to women and women started to pay special attention to language. Judith McDaniel says in Dale Spender's Men's studies modified: "If feminism is the final cause - and I believe it is - then language is the first necessity" (Jenkins and Kramarae, 1981, p. 13). Women's speech, women's discourse, women's subjects and other things were investigated and used as a basis for the position of women in general in society. The generically used masculine pronoun received much attention from both male and female linguists studying linguistics from a feminist viewpoint.

These researchers "[...] believe that language is profoundly political and that men's control of women is intimately tied to control of naming and restrictions on what women can say, when and where" (Jenkins and Kramarae, 1981, p. 13). Because the impact of feminism on linguistics was so strong and happened in so many different aspects of linguistics, I would like at this point to limit my observations to gender in language as it has been discussed up to this point.

It seems as if one of the reasons for the interest of feminist in language is the fact that feminine nouns in English are much more often derogatory or sexist than masculine nouns. Deborah Cameron (1985) even says that language is sometimes blatantly offensive towards women, or plainly androcentric, implying that the norm of humanity is male. Especially if the feminine nouns are the direct counterparts of the masculine nouns, we find duke and duchess, prince and princess, count and countess, but master 
and mistress, governor and governess. The master is the ruler of the house and the mistress is the woman doing sexual favors to this master. The governor is responsible for political matters in his state and the governess has a low paying job taking care of somebody else's children. The balance between men and women seems to be almost non-existent. The gender balancing in the English language is not a successful balance since, as mentioned before, everyone and every noun in English is masculine / male until proven otherwise, feminine / female. If we take a look at the all-inclusive term mankind, our understanding should show us a group of homo sapiens ${ }^{35}$ of both biological sexes. If we take the feminine term, which should not make too much of a difference, because we are still talking about a group of homo sapiens, womankind, it will trigger imagery of only women in our mind/brain. The definitions of male terms and of female terms are therefore clearly not balanced, since the connotation of the male term is usually also more respectable than that of the female term. Dennis Baron notes: In treating the masculine sense of the word man or one of its derivatives, such as manly, dictionaries frequently cite the supposed masculine qualities of strength, bravery, and firmness, while definitions of woman and womanly are either vaguely neutral, for example, 'having the qualities of a woman,' or they reflect complementary negative views of the sex as weak, timorous and changeable. Some of these positive and negative meanings are a function of the general cultural approbation or aggrandizement of the masculine, and derogation or trivialization of the feminine, and while their existence is unfortunate, their appearance records a fact of linguistic and social history. (Baron, 1980, p. 141)

This connection between linguistic and social history shows the position of the woman in language and society until today as different from that of men. I believe that language 
plays a major role in the positioning of women in society, and that especially the generic and supposedly unmarked pronoun he takes part in the supremacy of men in society.

As I said in chapter 2, the most influential grammarians who are responsible for much of the language change and the positioning of the generic masculine in language were in fact men. We can therefore securely talk about antifeminism in linguistics which to some extent prevails up until today. Antifeminism is only one term to denote what went on and still is going on in the field of pronoun usage in language. Ann Bodine calls the language itself androcentric, and Anna Livia even goes so far as to use a term coined by Jacques Derrida: phallogocentric. Livia titles her book Pronoun Envy, which in itself is a felicitous term for a biological phenomenon turning grammatical. Women, how are said to be suffering from penis envy, since the man's penis is the crucial body part separating her from power, not only envy the man's penis and therefore his superiority in the world, but also his claim on the generic pronoun in English.

The phallus is the ultimate difference between man and woman and it is only logical that it will turn to be the center of envy. If it is only for the phallus that men have more power than women, women will want the phallus as part of themselves and men need to protect it from women in order not to lose it. ${ }^{36}$ However, with phallogocentric we see a shift of blame from the women to the men. It used to be that the women saw language as androcentric. The grammarians were against the rights of women and were therefore considered antifeminist. The grammarians' power influenced language so much that the position of women in society was doomed to be inferior in comparison to men's position. It were the men who exercised their power over language openly and who dismissed any argument from women as feminist statements which cannot be taken seriously when the focus is the science of language. The term phallogocentric puts the women in 
the position of those who actively want the privileges of men. Or, if not the privileges, it is the phallus they are envious of, which by definition is the only thing that truly distinguishes men from women. Because women do not have a phallus, they are in fact women. The connection to language and pronoun envy is in the way that men have the generic pronoun, and women are thus rendered invisible. I will elaborate more on this point of view in my last chapter.

Quite a few female linguists and a number of male linguists are more and more fighting for the cause of women in language, and a tremendous amount of literature exists about the male / female differences in language and communication. Not only contemporary language is analyzed in detail but also language in the past and the change of language through its speakers. Dale Spender even calls English a Man Made Language, undoubtedly because of the overwhelming number of male grammarians who prescribed English to what it is today. There has to be, however, a different viewpoint to the whole discussion, which I will also lay out in the next chapter. I personally do not believe in the misogynist worldview feminist linguists seem to complain about ${ }^{37}$. But more on this later in chapter 5.

When talking about natural gender languages and their definition of masculine and feminine and maybe neuter nouns, we can still see that gender is only natural as long as one is male, because masculinity rules over femininity. In the following section I will talk about sex biased language. In this respect I will look at the language and its users, intentions of speech acts, connotations of vocabulary and their actual use and connotation of this use. We will see that the actual use of some words results in meanings different than the meaning given in the dictionary. 


\subsection{Sex biased language - sexist language}

Sex biased language is discussed in many books, both of a scientific and popular nature (Cameron, Tannen, Frank, Ashen, Glass, etc.). Information about sex bias in language sells well in the advice section of a bookstore as well as in the section for communication studies in a university bookstore. And it sells even better when it is called sexist language, because this seems to come across as more violent and degrading, and it appears as if everybody knows who the victim of this sexist language is. Most of the time we are right when we guess that it is in fact the female population and not the male. This condition of already knowing who will lose in the game has a tendency to become polemic and pathetic in its nature and I will try to stay away from sentiments of an angry kind. To keep this section more or less objective and academic, I need to focus on what sex bias in language really is, and which forms it takes. I will try to stay away from too much speculation, even though it is always hard to prove certain behaviors of speakers with respect to their sex bias since no one will admit to their own biases and prejudices.

When talking about sex bias and language there are two sides to the coin. The first is that of the language itself as we can see it in the type of vocabulary we use. Which biological sex is worthier and more frequent in a language and what effect does this have on the speakers of this language? The other side is the sex bias of the speaker of the language. Which words receive which meaning when and why? Can we conclude reasons for the position of either sex in society from the language spoken in this society? I will say more about the feelings of the speaker about the language spoken in the last chapter of this thesis, when I explore the notion of language awareness. 
Let's look at language and its own sex bias in the form of vocabulary first. It has already been mentioned that most words in the English language are masculine unless further specified. This might not appear to be problematic at first sight. The fact that the meanings of the masculine words are more often positive than negative also appears as easily acceptable if it wasn't for the fact that the feminine words, which are supposedly the opposites of the masculine words (master / mistress, bachelor / spinster, etc.) have mostly sexual overtones or are derogatory in their meaning. This seems to indicate that the English language as a system for communicating ideas and thoughts embodies sexual inequality and that this inequality is not in favor of women. Studies implementing word counting showed that there are 220 words for a sexually promiscuous woman but only 20 for a sexual promiscuous man (Spender, 1985, p. 15). Word counting is a good way to prove gender bias, or sexism, as it is most commonly called in literature, in a language. However, just the existence of sexist words does not explain the situation of women in society, and only because we find words in a language that show women as weak, sexually promiscuous and generally uneducated does not prove that they are in fact as they are described to $b^{38}$. The existence of these words that favor men and put women in a subordinated position in relation to men has brought forth a wave of neologisms; new words whose aim it is to be gender inclusive, political correct and unmarked by sex. We have moved away from police man and are now talking about a police officer, the chairman of a committee is now called a chairperson, or just chair (even though the fear of confusing the holder of this office and the furniture piece has actually been voiced), but we also still encounter female flight attendant, implying that a flight attendant in general is male unless further specified ${ }^{39}$. 
Sexism in language is therefore alive and well since we are still using terminology that singles out women and gives them a special place in language. A legendary article in the Harvard Crimson, the newspaper of Havard University written by the male scholars of the Harvard Divinity School assured a group of agitated women that the masculine pronoun was the best choice when talking about God, Man and Mankind, since it is unmarked and generic and that there is no need for pronoun envy at all (Livia, 2000). According to the article, the masculine pronoun would 'embrace' the feminine pronoun and the feminine side of the speakers. This instant of pronoun envy has been motivating linguists to write on this subject for many years now and still continues to do so. Clearly, the problem therefore is that on the one hand women are included and rendered invisible by language, and on the other hand there are still word coinages intended to include all genders in one word but which still single women out of the group of men.

An alternative proposal about the change of language is that language is in fact a mirror of society, and that language will not change until society does. What this effectively means for the treasure of words in English in particular will be discussed in section 4.2.

The other side of the coin for the claim of sexist language is in fact the user of the language, the speakers. "Since languages live in their users, it seems more appropriate to speak of language users as sexist, not the languages themselves" (McConnell Ginet, 1980, p.5). Do we really have to blame just the speakers of the language or is not the claim that the vocabulary with which these speakers have to work the true reason for the sexism in language? The speaker of a language without any misogynist terminology may feel strongly antifeminist, but they would have the obstacle of the 
lacking vocabulary, which would actually keep them from uttering the antifeminist thoughts and thus creating a hostile atmosphere towards women. I cannot, of course, claim that the vocabulary of English and the fact that English has the epicene (common gender) pronoun he makes all speakers of English misogynist, potentially antifeminist and the women necessarily phallogocentric, but it seems to me as if the influence of vocabulary is so strong that speakers may in fact be lead more easily towards hostility against women because of the above mentioned facts. It is a question of a speaker's language awareness. This language awareness may or may not lead to the speakers' careful choice of vocabulary. It is not only the vast amount of words each speaker has in their mental lexicon, but also the choice of words actually used. If this choice is determined by knowledge about the meaning and connotation of the words, then the speaker may successfully speak gender inclusively and non-discriminatingly. "It is clear that speakers can make conscious changes in their language habits if they have information, interpersonal relationships, and professional situations which support language change" (Bate, 1978, p. 148). A remaining question shifts the attention away from the vocabulary and away from the intention of the speaker towards a reason for the speakers' choice of words. If all speakers of English were to read in a newspaper and hear on radio and television broadcasts tomorrow, that the new and officially recognized epicene pronoun is in fact they and no longer he, would this really change the use of the language and the frequency of the generic he in English, or do we need more information for the language users before they will change their speech habits?

\subsubsection{Language and gender}

The feminist critique of language and gender can be traced all the way back to the Greek empire, in which the Greek grammarian Protagoras encoded masculine, feminine 
and neuter gender in language (Cameron, 1985a). Some 'exotic' languages like Swahili display more than three genders in their grammar. These genders are in these cases not tied to their naturalness, but rely on characteristics such as substance, consistency, ability of movement and so on. They may in fact be considered noun classes rather than gender. As discussed before, gender in language can be natural or grammatical. The connection between grammatical and natural gender and the meaning of the word is completely arbitrary. While the Greek sophists still believed that the great legislators gave language and therefore the meaning of words was essential to the words themselves, we conclude today that the connection between form and meaning is arbitrary. Jakob Grimm, the German grammarian, had his own explanation for grammatical gender:

Grimm believed that grammatical gender was a later stage of natural gender, which developed when speakers of a language passed from mere recognition of male and female beings to postulate a male/female principle in whose terms anything might be abstractly classified (Cameron, 1985a, p. 21).

The move from the recognition of differences between biological sexes to the distinction of inanimate objects and their gender assignment must have been led by some sort of guidance. When we return to the reasons why the masculine pronoun he may be used as the unmarked generic pronoun in English, we see that one of the prerequisites a word must fulfill in order to be considered unmarked is that of frequency. How is this frequency established? In the case of he, is it really a fact that there are more men, who are the primary semantic load of he, in language than there are women? Or are men more talked about than women are? If they are, what may be the reasons for such neglect of women? Couldn't it be more the reason that the generic pronoun was 
encoded in the language and that therefore, because of this encoding, the generic he was more frequent than any other pronoun? So if Grimm's assumption and the eventual encoding of he as the generic and unmarked pronoun in English fall together, then the feminist assumption that the English language is sexist may in fact be true, because it gives rise to the thought that women are less important, less talked about and not as frequently mentioned as men. And not only females are less talked about but also feminine nouns are less frequent than masculine nouns in language. A remaining question certainly is whether the encoding of the masculine pronoun as the generic in English has had any influence on the more frequent occurrence of masculine nouns in English or not. However, I believe that the answer to this question leads into the field of language change and language renewal, which are two fields I am not familiar enough with to implement them successfully in this thesis. To come back to my initial claim of the masculine holding more positive characteristics than the feminine, I will now look at some of these characteristics in comparison to each other.

The characteristics of a masculine object differ from those of a feminine object in that they are stronger, more reliable, possibly bigger and so on. "The masculine means the earlier, larger, firmer, more inflexible, swift, mobile, productive; the feminine the later, smoother, smaller, the more still, suffering, receptive" (Grimm, Deutsche Grammatik, 1831; quoted in Cameron, 1985a, p. 21). Whether all of the characteristics given for the masculine are in fact better than those for the feminine may certainly be subjective, but in connection to the time in which Grimm wrote, the masculine characteristics were probably more prestigious than those given for the feminine. If we turn to other languages than English we can see many instances of obvious differences even in appearance of many nouns. In French we find le chateau (the castle), but la 
maison (the house), and many other instances where the masculine noun is larger in size than the feminine noun (Cameron, 1985a).

I believe that we need to reject the theory of grammatical gender as being completely independent from sex and that the grammatical gender is only formal in nature. We can see that speakers, both academic and nonacademic, tie certain values and meanings to the words they use and that the application of grammatical gender makes these ties visible. We absolutely need to make a distinction between words originating in a language and words that have been borrowed or implemented into a language, but even for the neologisms in a language or for borrowings, gendered languages will assign gender and this special assignment will follow certain rules. In German a grammar rule states that words which do not originate in German and are borrowed from other languages (e.g. das Auto, das Hotel, etc.) should receive the neuter gender. However, especially in recent computer terminology we find many words taken from English which have been assigned genders other than the neuter. Die Diskette (the floppy disk) for example is feminine, but the computer becomes der Computer and thus masculine. ${ }^{40}$ Again we can see a pattern of the masculine being bigger, more influential and more important, and the feminine as the carrier of things, the suffering state and the less important object.

Men and women have different characteristics. They are different in many ways, some of which are biological and anatomical and others hypothetical. Women are commonly referred to as the weaker sex. At the same time it is a medical fact that men would die in the process of giving birth because they cannot cope with the pain of childbirth. Women do not have the same broad shoulders a man has, and their muscles cannot build up as much as those of men, but it is proven that they are more enduring 
than men are and that their chances of survival under strenuous circumstances are higher than those of men. So if women give birth, and therefore keep mankind alive, ${ }^{41}$ why is it that men are supposedly stronger and more reliable and therefore deserve to be unmarked and generic? Why do we talk about mankind and are supposed to assume a group of people of both sexes, but we can only assume women when we talk about womankind? How close is the connection between sex and gender in language really and which gave way for the other?

I agree with Deborah Cameron who says that the connection between grammatical gender and sex is not and cannot be arbitrary. She claims that a distinction has to be made at some point, but that we cannot say that one is independent from the other. However, at the same time, any attempt that tries to connect grammatical gender and sex on a one-to-one basis is also wrong, because we have to keep in mind that we are talking about a function of language and not about animate objects with obvious biological sexes dancing around in the speaker's mind.

\subsubsection{Language and sex}

When talking about language and sex, we have to again differentiate certain subcategories. What exactly is language in this context? What is its relation to sex? Is sex in this context the biological sex of the speaker? Or are we talking about language in relation to both biological sexes and are investigating their uses of language and the influences of this use on the other sex? In this section I will try to bring light behind these questions and will then relate them to the next section, the understanding of the influence of language on culture.

Language in the context I am talking about is the language we use in everyday life to communicate. This communication is mostly spoken communication and a lot of other 
rules apply to language if it is taken from the speaker to the writer. However, it appears as if the feminist understanding of language is actually not the understanding of spoken language but of writing. The relation of language to sex is as a matter of fact more easily seen in spoken language, because there are many prosodic differences between the language of a man and the language of a woman. However, are we talking about the same thing when we have the deeper voice of a man and call this male language, and the higher pitch of a woman as female language, and then turn to the use of vocabulary and the presence of the generic he and complain about the male language overriding the presence of women? I don't think so. When we are talking about language and sex, we have to move away from the sound properties of language as men and women use it, but we have to move more towards a theoretical approach in which we analyze the vocabulary and the semantics of language.

We need to move away from biological sex, because even though it does make a difference who is doing the talking and therefore determines the choice of pronouns, but the sex of the speaker does not influence the meaning of the words used. When talking about language and sex we need to look at language itself, and the possibility of assigning a sex to language itself. If the reason for the pronoun he being generic is that it is more frequently used, then the easiest way to determine whether English is male or female would be to count the instances of masculine nouns in relation to feminine nouns. If the masculine nouns are more frequent that the feminine, which they most probably are, given the generic masculine pronoun, then the language must be in itself male. Too far fetched? Maybe. But maybe not. If we turn back to ancient Greece, we find evidence that many gods were initially goddesses. We find that language in general showed more instances of femininity than masculinity. We can find in and outside of 
Greece, before antiquity, many civilized cultures in which women were the rulers and men were the servants. Matriarchies were frequent and successful. ${ }^{42}$ However, at the advent of written language, language became the domain of male scholars. In Greece, this resulted in additional phalluses on already existing goddess statues and changes in mythology. These changes were rather easily done since mythology and everything else was not yet etched in stone but relied on a narrative history. ${ }^{43}$ In the Greek world we then find the first and most influential grammarians who influenced our grammar rules until today, and the rest is history.

The question remaining is in which way language influences people? How does the language used by a man influence the position of a woman in society? We cannot really talk about women's language and men's language when we talk about English. Languages like Japanese have in fact two different sets of vocabulary for males and females. English does not show this obivious difference, where it is ruled which words may be used by a man and which may be used by a woman. There are certainly some words that are more often used by women than by men, but there are no grammatical rules as to the usage of these words. For English, we rather have to define the two different styles as a more and a less powerful variation of the same language. Robin Lakoff claims that "women's language has nothing to do with femininity per se, and everything to do with women's subordinate status" (Cameron, 1985, p. 167). However, this does not explain the position and the reason for the position of women as the subordinate group in an English speaking society. Why is it that women are subordinated to men? I don't know if the answer to this question can be found in linguistics or whether we need to look at society as a whole to find an answer. If women's language is the language of the oppressed portion of society, then all women 
should take assertiveness classes and learn how to speak like a man and all problems shall be solved. It somehow appears to me as if that is too easy a solution to the problem and that the real answer lies somewhere else. It is not language that makes women the subordinate category in relation to men, but it is the fact that patriarchy is the prevailing pattern of society and that men are rulers, definers of rules and hold the power to situate individuals in certain spots in the hierarchy. Changing language use patterns will probably not change this, but language awareness changes might be of some help. I believe that the patriarchical structures in society are not obvious to everyone living in this society, and that an awareness raising starting with language will open many eyes to these hierarchy problems. I will talk about language awareness more in my last chapter, chapter 5.

But before I jump into the self-understanding of the speaker, I want to look at the feminist understanding of linguist relativity and determinism, the Sapir-Whorf hypothesis.

\subsection{The feminist understanding of the Sapir-Whorf hypothesis}

How is the feminist understanding of the Sapir-Whorf hypothesis different from that of all other people on this earth (or maybe just that of linguists who accept the SapirWhorf hypothesis as a valid theory of the interplay between language and culture?)? Well, feminists found their cause in language because of its sex bias against women. The fact that so many words in the lexicon for English show sexist terms for women and respectable terms for men gives rise to the thought that the understanding of the position of men in the society of English speakers is much better than that of women and that women are therefore members of a lower group in society. If we connect this 
understanding of the position of women with the economical status' of many women in society, we see that women still in today's day and age are paid less money than men for the exact same work they do, and that women have only recently acquired the right to vote, to own property and to get a higher education. These are all privileges of men in society and became only rights for women.

The Sapir-Whorf hypothesis is split up into two different versions. The first, the linguistic relativity suggests that different cultures classify reality differently, it is therefore a different reality depending on the interpreter. This interpretative reality sticks with each individual. The second notion, the linguistic determinism is the belief that linguistic structures are responsible for their user's concepts of the universe. The understanding of the hypothesis therefore suggests that the personal reality is dependent on the individual language.

If a language displays a much higher frequency of masculine words, it is no wonder that women feel left out and invisible in such a language community. If we can agree on the moderate version of the Sapir-Whorf hypothesis, the linguistic relativity theory, which appears to be the theory most accepted among feminist linguists, then we can see that the vocabulary of English influences the imagery in the mind/brain of the speakers to an extent in which women are indeed rendered invisible and men dominant and obvious. In various studies the effect of the generic pronoun he has had the effect of male imagery in the heads of the participants. The participants are usually both men and women. An interesting distinction has been found by Fatemeh Khosroshahi (1989). She distinguished between traditional and reformed speakers of English when she conducted her study in a college setting. Traditional students were those who used the generic he in the papers they wrote for school and reformed speakers were those who 
used he or she, or they in their papers. Khosroshahi found that both male and female traditional speakers using he in the study reported dominant male imagery, while the reformed speakers reported a bigger number of women in their mental imagery. Khosroshahi titled her article "Penguins don't care, but women do: A social identity analysis of a Whorfian problem". The choice of title is very interesting, because it shows another marginalized group. Penguins are in the same category as birds. However, they 'suffer' from subcategorization in the bird society because they cannot fly. When we think about birds we will see our culturally acceptable bird in our mental imagery and the bird will have wings and will fly, since this is the main characteristic of birds. Penguins appear only marginally in the prompt imagery when we are talking about birds. The same subcategorization problem seems to apply to women. Since the generic pronoun is he, and the generic term for human is man, the imagery will produce a male human first and then a female human.

Grammatical gender categories are obligatory and are a result of natural gender assignment. Since we have the male and the female sex in general in our society we also have a majority of male and female gender in society. As mentioned before there is always a chance to cross the gender borders for the individual human. The question is, nevertheless, how much these gender categories are an actual product of language, which may have produced differences that need not exist. This seems to me the point where the feminist understanding of the Sapir-Whorf hypothesis is somehow different from the ordinary. It appears rather simple and convenient to blame the undoubtedly unfortunate position of woman in society on this hypothesis and eventually blame it on language. As I said before, I believe that the problem lies deeper than grammatical conventions. In my next section, the last one for this chapter, I explore the reasons, the 
advantages and disadvantages and the possibilty of maybe not needing a new pronoun in English after all.

\subsubsection{The need for a new pronoun}

A pronoun including both men and women in English seems to be necessary. Many things in society concerning women and the position of women in particular are rather unfortunate. Many linguists, both male and female, claim that the generic pronoun he is the source of all evil. But the way I see this problem it is not so much a problem of the generic pronoun which happens to be the masculine pronoun he, but more a problem of cultural connections and images inside the language user's mind / brain. Imagery happens inside people's heads, and it happens involuntarily. There is no one standing in front of the speaker showing pictures of men or women when certain words are uttered. There also isn't a sex-biased little man in the speaker's ear who suggests the 'correct' sex of the subject talked about. It is rather society and culture which produce imagery in connection with nouns, pronouns and certain professions. It is claimed that those professions associated with women are those of service, social or sexual, and that those associated with men are professions of strength and justice. The masculine is the positive and the feminine is the negative. This appears to be just another unpredictable stereotype. What is negative about a nurse? And what is positive about a thief? Nurses are traditionally female. However, larger numbers of men appear in the profession in the last decade or so. There is therefore the possibility of a male nurse walking into a hospital room to change the bedpan. The so-called profession of thief is traditionally masculine. Only seldom do we find thieves working in a Robin Hood manner, and distributing the stolen goods among the poor. This would in fact be a positive manner, but unfortunately not one associated with thieves in general. Even 
though thief is a common gender noun, including men and women, it has received masculine connotation, and eyebrows are raised in disbelief if news is cast about a female thief. It seems as if the number of thieves in department stores do not count for the profession of thieves in general, since department store thieves are frequently more women than men.

As we can see, the connotations of words are largely dependent on the individual. The generic pronoun he is certainly a problem and the question whether a new pronoun would change the understanding of many things as being either inclusive of both sexes or female in general remains unsolved. In my next chapter I would like to try to find some sort of answer for the language dilemma of women. I talk about the language awareness of the speaker, and how this language awareness may be changed in favor of women. 
5.0. Now what? The 'chicken and the egg' question.

The discussion about the generic pronoun he has been examined from several different angles. We have seen the feminist stance on the subject and we have seen the grammarians' choice for the encoding of he as the unmarked generic in the English language. At this point I would like to discuss the language awareness of speakers using he or other pronouns as their choice for the generic pronoun. What is language awareness and why is it important in the discussion about generic pronoun? Which comes first? The knowledge and therefore the awareness about he as being generic but at the same time exclusively male? Or the actual language use and then a possible thought on the primary meaning of $h e$ ? Which influences have to be in place in order for language to change? Why does Dennis Baron call the epicene pronouns "[t]he word[s] that failed" (Baron, 1980)? Have they really failed, or is the fact that there is such a long and on-going list of neologisms for the generic pronoun position evidence enough for the success of the movement? Can a change in pronouns really trigger what the feminists want, namely not only a change in pronominal use but also a change in the awareness of the speakers? Or does society have to change first in order for a pronoun to change?

My assumptions in the following chapter are just that, my own theories on language change and language awareness. I do not propose to hold the eternal truth about this because I believe that awareness of speakers and their interpretation of lexical items such as pronouns cannot be stamped as true or false because each speaker is individual in their choice of words and individual in their interpretation of these words. What I am doing in this chapter is pulling thoughts from other linguists about language 
change and language awareness and relating them to my own experience as a non- but near-native speaker of English, and the experience I have had concerning the movement from generic and unmarked he to singular they in everyday spoken English in North America in the past ten years.

\subsection{A change in pronoun, a change in awareness?}

If a change in pronoun, either a change to singular they, the more frequent use of he or she as seems to be happening, or the introduction of a new pronoun, a neologism could actually change the awareness of the speakers, then why does that not happen? The primary meaning of he is evident. No one does not know that he denotes the masculine object or subject in a sentence. The secondary meaning is that of the unmarked generic pronoun. This meaning, however, has to be learned through instruction and learning mechanisms. If the generic and unmarked use of he was acquired through language acquisition processes, then it may in fact seem as if everybody is masculine unless proven otherwise. But in my opinion that is not the case, because both girls and boys are aware of the existence of women in society, and using the generic masculine must strike them as rather odd until they are taught the difference between the primary and the secondary meaning of he. If the awareness of the speakers were such that they are aware of both the primary and the secondary meaning of he, then they would all understand the feminists' outrage about the concurrent use of he as a generic. The remaining question is that of the instruction: Are children actually taught this difference in meaning between the primary and secondary meaning of he? Fatemeh Khosroshahi called those speakers that were aware of the secondary meaning of he, the generic meaning the reformed speakers, and those only aware of its primary meaning the traditional speakers (Khosroshahi, 1989). The fact that there even are 
traditional and reformed speakers should be enough to show that the awareness of the speakers of English is in fact not so thorough that they will see and detect the difference in meaning when encountering he in any sentence and any environment.

Meanings of words can in fact change over time. Words acquire different meanings with different usages. Gay used to mean bright and happy and today is narrowed down to meaning homosexual. The use of gay ever since its change in meaning is less frequent not only because the meaning but also its connotation has changed from a word that could be used without second thought as an adjective to describe something positive to an adjective that denotes a minority which is not necessarily considered in a positive light. To use the word gay in any given context makes listeners question the meaning of the word and sometimes even the intent of the user. What is supposed to be brought across and why did the speaker pick this word in particular?

This is just one of the many examples that language change is in fact possible. Considering the generic pronoun he, we have to acknowledge, that this is both a social and a linguistic problem. The generic is not truly generic for the above given reasons. This is the linguistic problem. In order to make he truly generic we need to either redefine the principles of what is marked and what is unmarked for this special case, or we need to get rid of the primary meaning of he, the masculinity. He as a generic is a social problem for the speakers of English because they live in a society with accepts the superiority of the male over the female and because this superiority results in inequality and linguistic invisibility for women.

Which options are available for the change of pronoun? According to Dennis Baron, quite a few neologisms have been introduced but none made it into actual language use. The most commonly used alternative for he is, however, they. They is used in 
informal speech and is working its way into formal speech and writing. He or she is also used in conversation. Some handbooks on academic writing have taken they into their guidelines for non-sexist writing, and this is, in my opinion, a first step towards acceptance of they as an unmarked pronoun. $S / h e$ is sometimes used in writing, but lacks the possibility of language use since it is not pronounceable. And it also carries the stigma of awkwardness and inelegance. She is clearly gender marked and not a good substitute for he as a generic as the whole discussion is bound to restart again. There are a lot of reasons for the use of she as the generic pronoun of English, but they are all dependent on the feeling of fairness of the speakers, and since English is spoken by a people which is male dominated, the feelings of fairness after all these years of using he as a generic and giving she its turn as the generic pronoun are more than predictable and as a matter of fact obvious.

To change a pronoun in English is hard to do in any case, and in particular in the case of the generic pronoun. Many speakers and language purists will jump to their feet and cry censorship and claim their freedom of speech. It is claimed that the whole discussion about the change of pronoun is like brewing up a storm in a teacup. Education of speakers is said to be the best way to change the awareness of speakers and to improve the educated use of pronouns. Censorship and freedom of speech are heavy and important factors for language change. English, unlike French, does not have a language academy, which watches over the use and abuse of English, and because of this lack of authority we did have many language changes and implementations of vocabulary from other languages into English in the past. And we do have censorship affecting our daily speech. But we do not recognize it as such. The use of ain't in publications and formal writing is largely regulated. Every writer wanting to get their 
work published will refrain from using ain't. Cussing is not allowed in formal speech, and racist terminology is taboo. This is a form of censorship and an impairment on the freedom of speech that is widely recognized and accepted. Why is the fact that a thesis like this is still written today and suggests a different awareness of speakers and the then possible change of pronoun supposedly censorship? Maybe because the people censoring others are men, and they do not see anything wrong with the use of he as a generic pronoun.

Another alternative to the already existing pronouns could be the invention of a new pronoun. Neologisms have been introduced in many different ways. But I believe that the acceptance of a newly coined word for a pronoun is harder to achieve than the change of meaning for an already used pronoun. Change is never welcome. And especially in language, which is so deeply ingrained in its speakers, a change is not considered something good, even if it in fact does the language good ${ }^{44}$. It almost seems as if the normal speaker is superstitious about any kind of language change. At the same time, when we look back in history, language change did take place and the changes from then are considered good today. Linguistic change is possible and it will change the awareness of the speakers. A great example is the change from Negro to Black, which took place in the 1960s in America and took about a year to be a complete change both linguistically and socially. Another example is the change from Mrs. and Miss to Ms. which was also successful in its acceptance. This was a change out of purely social reasons, and it works admirably today.

My point is that if individuals change their language use, they will affect others and their change of pronoun will change their and others' awareness. For instance, if English teachers today would prescribe the use of they as the generic and unmarked 
pronoun, then a new generation of language users would eventually leave the schools. They would not only write they as the generic, but they would use they as the generic and unmarked pronoun. The effects of the usage of they instead of he have been discussed above. If the English teachers would make their students write they instead of he, the students would think about the reasons for the change of pronouns, and this thinking would result in the change of language awareness.

The other way to tackle the problem of he as the generic in English is to change the awareness of the speakers first and then the pronoun, meaning that education comes before action. In my next section I will discuss the advantages and disadvantages of such a line of attack.

5.2. A change in awareness, a change in pronoun?

This approach to language change follows the assumption that social change precedes linguistic change. Robin Lakoff wrote in 1973 that this is true, and that therefore pressure on the pronoun system is a waste of energy. I can only agree to the first part, the order of change. I believe that the culture of a people to a certain extent influences their language. Social change will therefore eventually change the language. We can find many examples of this in English and in many other languages, and I do not find it necessary to repeat them at this point. However, a change in pronouns is also possible. Pronouns are members of the closed class of lexical items and therefore traditionally not subject to change, but we have indeed seen a change in pronoun in English, when English lost thou and thee and used you instead. This change was probably not welcomed by English speakers of that time, because it meant a change in their language use habits and these changes are cumbersome, as we know. But the 
change was done and these pronouns were eliminated from the closed class, probably closing it even more tightly around the remaining pronouns.

If the change of the generic he is only a social problem, then we need to identify the group of people who are most affected and who are most prone to actually change their language behavior. Who is affected? Women. They are, supposedly, oppressed by the male speakers, made invisible, they are reduced to their sexuality in many words relating to them and they are considered to fight against windmills, because the use of he is supposedly generic and not sexist and if it should appear to be sexist sometimes, then this is surely not intended and only a fault in interpretation. But, again, who is at fault in case of such an interpretation? Women. This seems to lead back to the thought of supremacy of men in English speaking cultures.

The answer to the question of language change seems to be an active pressure on the large speech community. The pressure should not take the form of superimposed rules and regulations about the use of language, but rather in a way that makes the speakers think about their language use individually. If speakers are educated towards the use of an alternative pronoun in place of he, then they will change their habits. But who is in a position to put active and effective pressure on the speech community? I am inclined to say that teachers, and English teachers in particular have the most powerful positions to actively educate people and to make them change their language habits. But, as I said, this is just an inclination. The truth seems to be that it is not the field of teachers who are most influential on students and therefore the new generation of English speakers, but that rather the media together with pop culture have a much larger influence on the language use of English speakers today. Neologisms sprout out 
of pop music almost daily and are taken into the active vocabulary of young speakers immediately. ${ }^{45}$

If rock and pop stars would start to use one of the neologisms in Dennis Baron's list of proposed generic pronouns for English, I am sure that this word would successfully make it into actual language use. Not only the pop stars would have to change their language use, but also the media, who constantly talks about these stars. If a noticeable change were to take place, if these celebrities who function as role models for many adolescents, were to give statements to the media about their choice of language, which sometimes has already been done when pop and rock stars are put on the spot for their slang use, then the media would publish this view, the followers of the stars would think how cool it is of their idol to respect women in such a way that they change their language use, and these adolescents would probably strive to change their own language use more towards that of their idol. If these teen idols could be convinced to fight the linguist's cause, then women and language and the feminists complaining about the oppression of women would have it made.

However, how realistic is my little scenario? Not very realistic, indeed. Language change can come about in an instant, as noted above. But it usually takes several decades. Judging from my experience of English in North America in 1993 and today, in 2001, generic he is losing its position to a generic and unmarked use of they. Language change is happening, and apart from language purists complaining about the ungrammatical use of the plural pronoun in singular situations, nobody seems to care about this language change. Quite the contrary. It appears as if speakers use singular they in informal speech without thinking about it anymore. If a linguistic item becomes so ingrained in the language that speakers do not notice themselves using it anymore, 
that speakers unconsciously make use of it, then I believe that this item has become part of the language in the function in which speakers are not aware of it any longer. This does not mean that I herewith pronounce singular they the new generic and unmarked pronoun of English. I rather propose that language change is noticeable concerning pronouns and that the notion of the closed class lexical items, which allegedly cannot be changed, needs to be revised. We also need to revise our understanding of generic and we can finally go back to he as the masculine pronoun. And leave he in this primary function, since this is the function it fulfills best.

The change of awareness has taken place, in my opinion. The feminist linguists were successful in opening people's eyes toward the problem of the generic masculine and its irony. The social change has happened. Women's rights are much more acknowledged and women are much better off today than they were in the 1970's. Women are more respected even in this culture and have claimed more of their rightful space. Not everything has been done that can possibly be done quite yet, but first steps have been made. I believe that it is only a question of time until they will be encoded as the unmarked generic pronoun of English. 


\subsection{Conclusion}

The generic pronoun he has been a problem in English for many years. It was widely accepted in its position as the generic for a long time, because it was considered a rule of the language. It had to be impeached because of its sexist repercussions by the feminists in linguistics. In this process, many things have been discovered in English and about English. It is a proven fact that English is androcentric. Many words and many figures of speech are slanted towards the superiority of men over women. To find a very basic example of proof of men being the main subject of language, what other reason would we have to talk about penetration, if it was not for the fact that English is spoken from the view point of a man. If it were spoken from the viewpoint of a woman then the same act should be described as enclosure?

Nevertheless, in conclusion, I would like to take up some of Deborah Cameron's points when she talks about the linguistic oppression of women (Cameron, 1985). In her last chapter of her book Feminism and Linguistic Theory she speaks of linguistic determinism as a myth. I agree with her in that language is certainly an influential determinant of the lives of people, but surely not the only and most influential one.

She also says that the male control of language is a myth since no group has the power to influence language in such a way that they can fix certain expressions in the language and exclude others from use. Male and female children both learn language the same way. The claims that boys will feel much more comfortable with English than girls do because the masculine pronoun is used as a generic can only be true to a certain extent. Girls and boys are already put into particular roles as it is. Of course they construct their realities from their viewpoint, which is the role pattern they are placed in. Girls are therefore in a female pattern and are not, which is claimed, pressed into a 
male pattern by the use of language. I agree with her on this point, too. The culture around us and the expectations of society have much more influence on the development of children than language can possibly have. I am not saying that language is just another cultural trait, but I agree that it has unthinkable importance, but I am saying that it is not the single determinant.

The oppression of women through language is not something that has been developed recently. It is also something that has to be questioned on many levels. Why is it that women are oppressed? Can they not use language in the same way to express themselves? Do they have to use a different vocabulary to express themselves? I do not think that they do. I believe that they may use language just as freely as any man, and that women's use of language is just as powerful as men's use. At the same time, I do not believe that there ever was an equal language situation, and I also do not believe that there ever will be. Even if the problems addressed by many feminists in linguistics and even the problems addressed in this thesis are completely solved there will not be a completely equal situation. I do not believe that linguistic reform is the solution to all societal problems. Some linguistic changes proposed by feminists are so complicated that they would make language useless and probably even elitist. But it cannot be wrong to draw the attention of speakers to points in their language that may be sexist, discriminating or degrading in any other way of a certain group, maybe even a minority of speakers. It is good to show that a masculine bias in English exists. However, if we keep writing books, articles and theses about this problem, about the weakness and underprivilegedness of women, we will eventually believe what we are writing and women will indeed feel weak, oppressed and underprivileged by language. This cannot be the goal of my endeavors. Language and language functions have to be made 
transparent. Speakers have to be made aware of the language they produce in everyday life. But they must also be presented with new ways of interpretation and of understanding meaning. It is the responsibility of every speaker not to use language as a mere vehicle of meaning but rather as a tool of communication. Instead of piling meaning onto a bandwagon, we need to choose the way of stacking this meaning. If we do not care about our choice of language, our load will fall off the wagon and be useless. If we are, however, skillful enough to mold our stack in a way that it becomes stable and perfectly carries and protects our load, then we have succeeded and are using language in a responsible way.

If this scenario of responsibility of language use can be followed, and our language awareness can be molded to perfectness, then we are able to take yet another small step towards language improvement for all parties involved in the use of language. And unlike a goal which we can reach, for example complete equality of speakers, equality of sexes, which is more or less desirable, the way we travel is the goal in itself. We are not controlled by language. We may be influenced by it, but once we confide in ourselves as speakers of our language, we overcome all difficulties connected with language. 
${ }^{1}$ Some of these definitions may be only partial definitions and some may be from other areas of study, but they are all important to this thesis and must therefore be included in this opening part.

${ }^{2}$ A famous example of misunderstanding of grammatical gender is Mark Twain's essay The Awful German Language. "In German, a young lady has no sex, while a turnip has. Think what overwrought reverence that shows for the turnip, and what callous disrespect for the girl." Twain deliberately mixes up biological sex and grammatical gender for purposes of humor. However, some linguists and non-linguists seem to, just as deliberately, overlook this humor, and voice their complaint about the arbitrariness of gender assignment in language out loud and with support of literature, but without further inquiry about the possible reasons of the gender assignment.

${ }^{3}$ The German words for girl displays neutral gender whereas turnip is feminine in grammatical gender. This is taken as proof that the gender assignment in languages is illogical. What fails to be mentioned, is that Mädchen (girl) is neuter because of the -chen ending, which serves as a diminutive, and has its counterpart in Bübchen, the masculine equivalent (boy).

${ }^{4}$ This is the declination in the nominative case. All items are singular in number.

${ }^{5}$ Unless we talk about a language like Chinese, which uses a genderless pronoun for nouns like this.

6 "A random foray into any newspaper will eventually reveal usages like the following: 'FOURTEEN SURVIVORS, THREE OF THEM WOMEN ...', or 'PEOPLE ARE MUCH MORE LIKELY TO BE INFLUENCED BY THEIR WIVES THAN BY OPINION POLLS,"' (Cameron, 1985, p.69. capitals in text.).

${ }^{7}$ This 'one' is not necessarily and all of the time a woman, but there are many men, who are strident defendants of women's rights and who are sometimes more radical than any woman would ever be in their opinions and expression of those opinions. The notion that a feminist is always a woman, preferably a homosexual woman (because, which other reason would there be for a woman to defend her rights against men if she doesn't hate men, which has to be the sole reason for homosexuality among women), belongs on the top shelf of all stereotypes.

${ }^{8}$ Generics is a term that I made up for my purposes. I have not found it in literature as an established term. I will try to explain what I mean by generics in this section.

${ }^{9}$ The story behind this choice will be given in chapter 2 .

${ }^{10}$ Marking theory, as Cameron puts it, can be divided into three principles. The first principle states that the item has to be able to be used generically in a way that it subsumes or includes marked variants (in this case, he including she, male including female). The second principle is that the item must have a relative neutrality of meaning. And the third principle is that of frequency of occurrence. If $h e$ is found more frequently than she then he is said to be unmarked.

${ }_{11}^{11}$ Singular they will be further mentioned in point 1.4. in this chapter.

12 This sentence is starred $\left({ }^{*}\right)$ because it violates rules of syntax. Further sentences violating such rules will also be starred to make this violation clear.

${ }^{13}$ This sentence, though a part of everyday language use, is starred, or marked as ungrammatical, because it violates the grammatical rules of antecedent agreement. Unfortunately, as with many aspects of syntax, this sentence is bound to be starred because of its violating nature, and the fact that this is a perfectly understandable sentence that is used by speakers of a language has to be left out.

${ }^{14}$ As mentioned earlier, syntax leaves out semantics, but in the course of this thesis, it will become clear that the semantics are important to the understanding of pronouns and that grammaticality as written in prescriptive grammars of English cannot be the measure for language.

${ }^{15} \mathrm{I}$ am fully aware of the changes in professions and language awareness in today's English. The reason I am mentioning these three professions at this point is a case of pronoun envy that has happened among teachers. Since most teachers traditionally were women, a teacher's manual changed the generic he to a generic she. It was not the group of female teachers who revolted against this use of the pronoun, or of the use of the masculine pronoun before that. It was the male teachers who demonstrated against their sudden invisibility in the profession.

${ }^{16}$ Most but certainly not all nurses are female, most but certainly not all doctors are male. I am aware of the problematic use of these generalizations about nurses, doctors and teachers. But I am also aware of the ongoing debate about the appropriate pronoun use for these professions and I therefore believe it rightful to use these common gender words to explain my theory. 
${ }^{17}$ As more and more women have taken up activities formerly reserved for men, languages that make gender distinctions in their nouns have had to accommodate their occupational titles. As long as it was unthinkable for anybody but a man to be a doctor, the word for doctor could remain comfortably masculine. But the new state of affairs forced a decision: either feminines had to be coined to match every masculine or the gender of the noun had become a formality. The languages facing this problem Polish for example - are still trying to decide in each case which of two variant forms to adopt. ( Bolinger and Sears, 1981 in Cameron, 1985a, p. 23)

${ }^{18}$ Almost everybody heard about the story of the father and son involved in a car crash. They are taken to the hospital where the son is getting ready for surgery. When the surgeon arrives in the OR, the surgeon says:"Oh, no, I cannot operate on this man; He is my son!" Why can the man on the table be the son of the father and of the surgeon? Because the surgeon is his mother. This story is still used to create a sort of wake-up call in Sociolinguistics courses when it comes to generic professional terms. And until today, this story puzzles students.

${ }^{19} \mathrm{I}$ am indebted to Dr. Laura Brady who pointed out to me that terms like deer and fox are usually taken as the generic form of the animal and further specifications as doe or vixen are only seldom applied. Since the understanding of the noun is generic it makes sense to use the generic pronoun in reference. This, however, shows the supremacy of the masculine over the feminine. Why is it that the fox is the generic and not the vixen? I understand MacKay's choice of the fox now better, yet see myself supported in my argument that the masculine is the generic and therefore more valuable than the feminine.

${ }^{20}$ This deity function was actually the reason for the article in the Harvard Crimson, which will be discussed later in this thesis.

${ }^{21}$ How hard and fast is the evidence that items cannot be added to the closed class of lexical categories in English? Open class words are supposedly easily created through compounding and verbing. Numerous attempts have been made to add new pronouns, and other pronouns have vanished from the language use. The remaining problem with closed class items is rather the actual language use and the actual semantic extension in the language and among the speakers. Additions to both open and closed classes have to be introduced and accepted by the speakers, and it seems as if this acceptance is the biggest obstacle in the creation of a new pronoun.

${ }_{22}$ As far as I know, the semantic feature [ \pm woman] does not exist.

${ }^{23}$ Tannen, D. (1990). You just don't understand: women and men in conversation. New York: Morrow.

${ }^{24}$ We all know of proverbs like Foxes are all tail and women are all tongue. Nevertheless, there are studies that prove that just the opposite is true, and that men tend to dominate women in situations like business meetings, where the actual speaking time is higher for men than it is for women.

${ }^{25}$ Language change and the movement of political correctness in language are in the process of changing these vocabulary items to more generic and neutral terms such as mail carrier and police officer. How successful this rendering of words is in the mind of the speaker is unproven to this point.

${ }^{26}$ Many texts by William Shakespeare display the use of they as the generic pronoun. This may either be a sign of the actual use of they as the generic or of Shakespeare's ability to mend language to his own uses. Many of Shakespeare's writings are deliberately kept ambiguous towards gender.

${ }^{27}$ Note that the opposite of masculine is not feminine but effeminate, and that effeminate is usually considered a trait of the homosexual man.

${ }^{28}$ The source for this section is almost exclusively Dennis Baron's work on Grammar and Gender. His listing is the most comprehensive of all, and his website also provides the interested reader with new additions to the list in the book. On the website he also lists the Klingon pronoun coined for the TV series Star Trek. See bibliography for the URL.

${ }^{29}$ If we only look at fashion trends and their communicated message, we can see a very intricate system of communication. Culture may in fact convey messages on many different ways, which, all in all, are too multifaceted to be listed here.

${ }^{30}$ The question as to how influential the single speaker of a language actually is, leads to a whole new thesis. Many linguists claim that the individual speaker cannot change the language of use. At the same time these speakers supposedly speak their own idiolect, thus creating their own language. If subsumed under one 'über-language', we see that all those ideolects not only make one language, but that they are also at the same time in constant change, due to their speakers. Yet another circular claim of definition.

${ }^{31}$ For further reading on immigrant experience, check Eva Hoffman, (1989), Lost in Translation. New York : E.P. Dutton 
${ }^{32}$ The Romans, united by Latin, were able to distribute their culture and army through the use of Latin all over Germania.

${ }^{33}$ I will say more about the Sapir-Whorf hypothesis in section 3.2. of this thesis.

${ }^{34}$ Or sometimes even Sapir-Whorf-Humboldt hypothesis. The problem is that if we keep adding names to it, we will soon see that names like Wittgenstein, Berkeley and Herder should also be part of it. A clearly phrased hypothesis in, say two sentences, does not exist as far as I know. Certainly quite a few influential philosophers and linguists took part in the formation of thought underlying this hypothesis, but I will limit myself in space here and will only refer to the hypothesis as that of Sapir and Whorf.

${ }^{35} \mathrm{I}$ 'm using this term now because it does get really hard to use words that are not gender biased in any way when talking about humans. Even the word human can be disputed because it includes the dreaded stem man in it. This is not only tedious but beside the point. However, for clearness reasons and out of respect for the many people who fight avidly against the androcentrism in language I will use this more or less technical term at this point.

${ }^{36}$ All of this phallogocentric of penis envy leads too far into Freudism and therefore too far away from my initial point in linguistics. I will therefore leave to this explanation at this point.

${ }^{37}$ It is not very easy to stay on safe ground when arguing against such a large group of people who are so educated and convinced of their points of views. I would like to make clear that I have a different standpoint on the language and gender discussion than the popular feminists in linguistics seem to have. I hope I can make this standpoint clear in my next chapter.

${ }^{38}$ However, language that is called effeminate and which is normally attributed to homosexual men carries even more of a stigma. Not only do the effeminate homosexuals speak like women (or should I say wimps?) but they are right in the middle of the promiscuity drawer of stereotypes. This is linked not only to their being gay, but also to their behavior and language. Stereotypes about homosexuals are many. See Kira Hall \& Anna Livia (Eds.) (1997) Queerly Phrased for further information on this subject.

${ }^{39}$ Not only is the thought of confusing the holder of an office in a committee, the chair, and the piece of furniture rather amusing, because it completely leaves out any kind of context in which we come across these nouns, but also the coining of the female flight attendant strikes me as odd, because the noun phrase flight attendant was installed in the language to replace steward and stewardess, and to prefix it with female renders the whole word coinage process as superfluous.

${ }^{40}$ Other words like email do not have a clear gender assignment, and people will assign their own perception of gender to it. This is interesting to observe since email may be feminine for some, masculine for others and neuter for yet again different people.

${ }^{41}$ Isn't this sentence yet another piece of evidence that the generic function of he and man is a joke? Mankind needs woman to reproduce, but they cannot give up the generic pronoun....

${ }^{42}$ The Musuo in southern China still uphold their matriarchy, but the Chinese government is doing everything in its power to deprive the women there of any help. Matriarchies are traditionally a threat to patriarchical societies and it is no wonder that the Chinese government is trying to destroy the culture of the Musuo women. To my knowledge, there has been no linguistic research done on the language of the Musuo women and men, but I assume that the fact of their cultural system is evident in their language. See Bubenik-Bauer, Iris. (2001)Die Heimat der Göttin Gemu. Die matriarchale Welt der Moso: Mythen, Riten und Legenden. Atlantik, Bremen.

${ }^{43}$ One of the characteristics of matriarchical society was the ignorance and neglect of written language. It was more important to have stories, legends and myths in a narrated form than to have them in writing. The intent of favoring the narrated form was to keep a closeness among the members of the group. Narration has to be done in a group, whereas reading can be done individually.

${ }^{44}$ See the current Rechtschreibereform(spelling reform) in Germany. Speakers are asked to change their orthography for many words, which have undergone changes in informal spelling already. The resistance to the reform is massive and certain regions are liberating themselves from Germany on the grounds of spelling. What the German speakers fail to see is that they have a spelling reform about every 100 years and the last one was beneficial for writing and speaking. But since this reform means change, speakers are afraid of it and it will take some time for the new rules to be accepted. The author feels a considerable amount of aversion against some of the new rules and spellings herself, but since publishers have already widely accepted the change, it will be publicized more often and as soon as the eye of the beholder gets used to the reformed language, the change will be successful.

${ }^{45}$ My favorite example is Californication, a word coined by the Red Hot Chilli Peppers in 1999, and which is active vocabulary of the Freshmen and Sophomores in the classes I teach. 
References

Adamsky, Catheryn. (1981). Changes in pronominal usage in a classroom situation. Psychology of Women Quarterly, 5, 661-69.

Baron, Dennis. (1986). Grammar and Gender. New Haven and London: Yale University Press. . The Epicene Pronouns: A Chronology of the Word That Failed. Available at http://www.english.uiuc.edu/baron/essays/epicene.htm

Bate, Barbara. (1978). Nonsexist language use in transition. Journal of Communication, 28, 139-149.

Bing, Janet. (1991). Penguins can't fly and women don't count: Language and thought. Women and Language, 15, (2), $11-14$.

Bodine, Ann. (1975). Androcentrism in prescriptive grammar: singular 'they', sex definite 'he', and 'he or she'. Language in Society, 4, $129-146$.

Cameron, Deborah. (1985). Feminism and linguistic theory. New York : St. Martin's Press . (1985a). What has gender got to do with sex? Lanquage and Communication $\underline{5}$ (1), $19-27$.

Chambers, J. K. (1995). Expressing Sex and Gender. In Chambers, J. K. Sociolinguistic Theory.Linguistic Variation and its Social Significance. Oxford, England:Blackwell Publishers.

Cole, C. Maureen, Hill, Frances A. \& Dayley, Leland J. (1983). Do Masculine Pronouns Used Generically Lead to Thoughts of Men? Sex Roles, 9, (6), $737-750$. 
Connor, Jane Marrantz \&Serbin, Lisa A. (1978). Children's Responses to Stories with Male and Female Characters. Sex Roles, 4, (5), 637 - 45.

Crawford, Mary \& English, Linda. (1984). Generic Versus Specific Inclusion of Women in Language: Effects on Recall. Journal of Psycholinguistic Research, 13, (5), $373-81$.

Henley, Nancy M. (1987). This New Species that Seeks a New Language: On Sexism in Language and Language Change. In: Penfield, Joyce (ed.). Women and Language in Transition. State University of New York Press. 3 -27.

Huber, Joan. (1976). On the generic use of male pronouns. American Sociologist, 11 , $85-93$.

Jenkins, Mercilee M. \& Kramarae, Cheris. (1981). A thief in the house: Women and language. In: Spender, Dale (ed.) Men's studies modified. Oxford, England: Pergamon Press. $11-22$.

Khosroshahi, Fatemeh. (1989). Penguins don't care, but women do: A social identity analysis of a Whorfian problem. Language in Society, 18, 505-525.

Lakoff, Robin.(1975). Language and Women's Place. New York: Harper Row.

Livia, Anna. (2000). Pronoun Envy. Literary uses of linguistic gender. Oxford University Press.

MacKay, Donald G. (1980). On the goals, principles, and procedures for prescriptive grammar: Singular they. Lanquage in Society, 9, 349-67. . (1983). Prescriptive grammar and the pronoun problem. In: Thorne, Barrie, Cheris Kramarae and Nancy Henley (eds.) Lanquage, Gender and Society. Newbury House Publishers. 38 - 53. 
Martyna, Wendy. (1978). What does 'He' mean? Journal of Communication,28, 131 138.

. (1980). The Psychology of the generic masculine. In McConnel-Ginet, Sally, Ruth Borker \& Nelly Furman (Eds.). Women and Language in Literature and Society. Praeger Publishers. $69-78$.

. (1983). Beyond the He/Man approach: The case for nonsexist language. In Thorne, Barrie, Cheris Kramarae and Nancy Henley (eds.) Language, Gender and Society. Newbury House Publishers. $25-37$.

McConnell - Ginet, Sally.(1980). Linguistics and the feminist challenge. In: McConnell Ginet, Sally, Borker, Ruth \& Furman, Nelly (Eds.). Women and language in literature and society. New York, Praeger Publishers. 3-25.

Miller, Casey, Swift, Kate. (1976). Words and women. Garden City, N.Y. : Anchor Press. . (1980). Handbook of nonsexist writing. New York : Lippincott \& Crowell.

Moulton, Janice, Robinson, George M. \& Ellias, Cherin. (1978). Sex bias in language use. "Neutral" pronouns that aren't. American Psychologist. 1032 -1036. Moulton, Janice. (1981).The myth of the neutral 'man'. In Mary Vetterling-Braggin, (Ed.) Sexist Language: A Modern Philosophical Analysis. NJ: Littlefield, Adams, \& Co., $100-15$.

Pyles, Thomas, Algeo, John. (1982). The Origins and Development of the English Language. Third Edition. New York, Harcourt Brace Jovanovich, Publishers. Quirk, Randolph, Greenbaum, Sidney, Leech, Geoffrey, Svartvik, Jan. (1985). $\underline{A}$ Comprehensive Grammar of the English Language. London and New York, Longman. 
Sampson, Geoffrey. (1980). Schools of Linguistics. Stanford, California, Stanford University Press.

Sapir, Edward. (1966). Culture, Language, and Personality. David G. Mandelbaum, (ed.). Berkeley and Los Angeles, University of California Press.

Spender, Dale. (1981). Men's studies modified. Oxford, England: Pergamon Press. . (1985). Man made language. London: Routledge \& Kegan Paul.

Tannen, Deborah. (1990). You just don't understand : women and men inconversation. New York : Morrow.

Whorf, Benjamin L. (1956). Language Thought and Reality. Cambridge: The MIT Press.

Woolf, Virginia. (1929). A Room of One's Own. New York, Harcourt and Brace. 
Appendix 1

Functions and examples of prescriptive he.

\begin{tabular}{ll}
\hline \hline Function & Example \\
\hline Mixed-sex distributive & $\begin{array}{l}\text { When voters elect a legislator, he has four years in } \\
\text { office. }\end{array}$ \\
A fox tucked his tail between his legs and ran off. \\
Sex-unknown & $\begin{array}{l}\text { Someone left his sweater. } \\
\text { Sex-concealed }\end{array}$ \\
Mixed-sex disjunctive & $\begin{array}{l}\text { During the closed session, one of the committee } \\
\text { members said he considered the bill worthless. } \\
\text { If either John or Mary comes, I will meet him at the } \\
\text { airport. }\end{array}$ \\
Deity function & God manifest Himself in many ways.
\end{tabular}

Functions and examples of singular they

\begin{tabular}{ll}
\hline Function & Example \\
\hline Mixed-sex distributive & $\begin{array}{l}\text { When voters elect a legislator they have four years in } \\
\text { office }\end{array}$ \\
A fox tucked their tail between their legs and ran off. \\
Sex-unknown & $\begin{array}{l}\text { Someone left their sweater. } \\
\text { During the closed session, one of the committee } \\
\text { members said they considered the bill worthless. } \\
\text { If either John or Mary comes, I will meet them at the }\end{array}$ \\
Mixed-sex disjunctive & $\begin{array}{l}\text { airport. } \\
\text { If Seattle calls tell them I'm out. }\end{array}$
\end{tabular}

Taken from: MacKay, Donald G. (1980). On the goals, principles, and procedures for prescriptive grammar: Singular they. Lanquage in Society, 9, pg.351. 
Appendix 2

Pronouns in Middle English

PLURAL

First Person

Nom.

Obj.

Gen.

Second Person

Nom.

Obj.

Gen.

ich, l, ik

we

me

us

mi; min

our(e); oures

thou

thee

thi; thin

ye

you

Third Person

Nom.

he

Obj.

him, hine

his

your(e); youres

hi, they, thai

hem, heom, them, thaim, theim

her(e), their(e); heres, theires

Nom. she, ho, hyo, hye,

he, scho, cho, he

Obj. hir(e), her(e), hi

Gen.

hir(e), her(e); hires

Nom. hit, it

Obj.

Gen.

hit, it

his

Taken from: The Origins and Development of the English Language. Thomas Pyles / John Algeo. Harcourt Brace Jovanovich, Publishers. 1982. pg.157. 